\title{
Characteristics and thermodynamics of Sahelian heatwaves analysed using various thermal indices
}

\author{
Kiswendsida H. Guigma ${ }^{1}$ [ $\cdot$ Martin Todd ${ }^{1} \cdot$ Yi Wang $^{1}$
}

Received: 1 October 2019 / Accepted: 23 August 2020 / Published online: 1 September 2020

(c) The Author(s) 2020

\begin{abstract}
Prolonged periods of extreme heat also known as heatwaves are a growing concern in a changing climate. Over the Sahel, a hot and semi-arid region in West Africa, they are still relatively poorly understood and managed. In this research, five multivariate thermal indices derived from the ERA5 database were used to characterize Sahelian heatwaves for statistical analysis and as a sampling basis to investigate their underlying thermodynamic causes. Results show that on average most locations in the Sahel suffer from one or two heatwaves a year lasting 3-5 days but with severe magnitude. The eastern Sahel is more at risk than the west, experiencing more frequent and longer lasting events. Despite similar statistics of intensity, duration and frequency across the heatwave indices, for a given diurnal phase, there is surprisingly low agreement in the timing of events. Furthermore daytime and nighttime heatwaves have little synchronicity. In terms of associated thermodynamic processes, heat advection and the greenhouse effect of moisture are identified as the main causes of Sahelian heatwaves. The processes are nevertheless sensitive to the indices, consequence of the distinctness of their respective samples. Therefore attention should be given to the choice of either index in operational monitoring and forecasting of heatwaves. This will allow to effectively target different exposed socio-economic groups and resultantly enhance the efficiency of early warning systems.
\end{abstract}

Keywords Heatwaves $\cdot$ Sahel $\cdot$ Thermal indices $\cdot$ Simultaneousness $\cdot$ Thermodynamic processes

\section{Introduction}

Heatwaves, extended periods of extreme heat (Gasparrini and Armstrong 2011) are increasingly recognised as a major hazard to the society, with impacts directly on human health (e.g., Guirguis et al. 2013; Arbuthnott and Hajat 2017) and important socio-economic sectors including agriculture (Smoyer-Tomic et al. 2003) energy (Añel et al. 2017), transport (Palin et al. 2013), infrastructure (Chapman et al. 2013) and tourism (Perry 2000). Recent illustrative examples of heatwaves that have caused major loss of life and global impacts through commodity supply chains include Russia

Electronic supplementary material The online version of this article (https://doi.org/10.1007/s00382-020-05438-5) contains supplementary material, which is available to authorized users.

Kiswendsida H. Guigma

k.guigma@sussex.ac.uk

$\checkmark$ Yi Wang

Yi.Wang@sussex.ac.uk

1 University of Sussex, Brighton, UK
2010 (estimated 55,000 deaths, Barriopedro et al. 2011) and Europe in 2003 (estimated 40,000 deaths, García-Herrera et al. 2010; Miralles et al. 2014). Indeed in Australia, heatwaves have been identified as the deadliest natural hazard (Coates et al. 2014). Under a warming climate there is clear evidence that heat extremes have been increasing in recent decades (Hartmann et al. 2013) and are likely to continue to do so under all plausible greenhouse gas emission trajectories (Collins et al. 2013).

The Sahel region of West Africa is especially vulnerable to heatwaves with mean temperatures and heatwave risks peaking in the spring and autumn seasons immediately prior to, and following the summer monsoon (Guichard et al. 2009). In addition, the Sahel population is extremely vulnerable to climate shocks due to dependence on climate sensitive sectors (e.g., agriculture), widespread poverty and inadequate provision of health services, amongst others (e.g., Davidson et al. 2003; Tschakert 2007). However, the literature on Sahel climate and society focuses overwhelmingly on rainfall variability and its societal impact and much less on the causes and impacts of extreme heat. Yet like other regions there are clear upward trends in Sahel temperatures 
(e.g., Guichard 2014; Moron et al. 2016) most notably during nighttime. Recent studies showed upward trends in duration, frequency and intensity of heatwave events over the past decades (Fontaine et al. 2013; Moron et al. 2016; Ceccherini et al. 2017; Barbier et al. 2017) and future projections also show a growing risk of extreme heat in the region (e.g., Nangombe et al. 2019; Rohat et al. 2019). However, some contradictory evidence of unchanged frequency exists (Adeniyi and Oyekola 2017), which may be related to the choice of heatwave index.

The negative impacts of extreme heat can, nevertheless, be mitigated, based on skilful forecasts (e.g., Ebi et al. 2004; Masato et al. 2015; Lee et al. 2016). Heatwave-health early warning systems are being developed in a number of countries, guided by the WMO-WHO (2015). Further, complementing national government systems, in the humanitarian sector systematic approaches to using weather/climate forecasts in risk management called Forecast-Based Action $(\mathrm{FbA})$ and Financing $(\mathrm{FbF})$ are being developed and implemented by the Red Cross/Red Crescent Society amongst others (Perez et al. 2018; Wilkinson et al. 2018) and are being applied to heatwave hazards. The relevant meteorological timescales for an efficient implementation of these plans are the synoptic and intraseasonal scales. In the Sahel the ACASIS (Sahelian heatwave early warning and their impacts on health) project advanced the scientific evidence of drivers and impacts of heatwaves (https://acasis.locea n-ipsl.upmc.fr/). Heatwaves have been routinely monitored by two national meteorological services in the Sahel namely in Burkina Faso and Senegal. Effective forecasting and risk management require nevertheless a clear definition and understanding of heatwave processes, especially at the short (synoptic and intraseasonal) timescales.

There is no conventionally accepted definition of a heatwave (Souch and Grimmond 2006). Various heatwave indices have been proposed, which often combine various environmental variables (humidity, wind and solar radiation) to represent the link between the physical phenomenon (heat) and the physiological issues (health or comfort) (e.g., Macpherson 1962; Cheng et al. 2012; de Freitas and Grigorieva 2015a, b, 2017). Further, the selection of thresholds of index intensity, duration and spatial extent varies across the literature and operational systems (e.g., Nairn and Fawcett 2013; Robinson 2001; Zhang et al. 2012; Perkins and Alexander 2012; Smith et al. 2013; Perkins 2015; Gachon et al. 2016; Xu et al. 2016, 2017). However, multiple heatwave indices complicates both (1) scientific analysis as the heatwave event samples and underpinning thermodynamic processes may vary. (2) Monitoring and prediction and early warning under conditions where predictability and the link to health outcomes varies between indices.

Because of above complication, our paper has two main scientific objectives: (1) to compare the statistical characteristics of high-frequency heatwaves in the Sahel using diverse multivariate thermal indices (see methods in Sects. 2.2.1 and 2.2.2, results in Sect. 3.1) and (2) based on these indices, to assess and compare for the first time the underlying thermodynamic processes driving the heatwaves (see methods in Sect. 2.3, results in Sect. 3.3). The variability of the thermodynamics across heatwave indices will give insight as to their robustness and by implication their potential predictability. Note that we do not consider here the large-scale dynamical drivers of heatwave events, which will be explored in a companion paper later.

The novelty of this research is that through its approach, it makes a connection between pure atmospheric physics and proved health outcomes (e.g., Black 2010) through the use of multivariate thermal indices. In addition, the comparative study of heatwaves characteristics sampled from different thermal indices is in itself original since over this region, to the best of the authors' knowledge, such an analysis hasn't yet been conducted. This study is also the first to investigate the thermodynamics of heatwaves at the synoptic to intraseasonal scale, and is thus relevant for $\mathrm{FbA} / \mathrm{FbF}$ plans.

The makeup of the paper is as follows. Section 2 details the methodology used. Section 3 presents the results both in terms of statistical characteristics and thermodynamic processes. Section 4 discusses the findings of this paper with respect to other published works and elaborates on the potential dynamical large scale drivers. Section 5 summarizes the study.

\section{Data and methods}

\subsection{Data and derivation of thermal indices}

To meet our research aims of comparing multivariate heatwave indices and determining the associated thermodynamic processes, a self-consistent multivariate dataset is desirable. The Sahel is a data-sparse region and so we have utilised the fifth generation of the European reanalysis (ERA5 hereafter) data regridded at $0.5^{\circ} \times 0.5^{\circ}$ resolution covering the 1979-2018 period (C3S 2017). We recognise the limitations of reanalysis data as a modelled dataset. But we also note that Barbier et al. (2017) have demonstrated greater agreement with observed temperatures over the Sahel for ERAInterim (Dee et al. 2011). ERA5 is an improvement of ERAInterim when compared to observations and other reanalysis products. Furthermore, Oueslati et al. (2017) have reported that the ERA-Interim reanalysis is able to capture very well the annual cycle and its interannual variability of the US heat-index (an index that is used in the present study over the Sahel). There is additional evidence that ERA5 is the reanalysis that offers the best representation of various near surface meteorological products including near surface 
moisture and wind speed (e.g., Olauson 2018; Ramon et al. 2019), which are used in this paper (see Table 1). ERA5 is therefore well suited to this research. Our study domain of the Sahel is defined as the continental area located between $20^{\circ} \mathrm{W}-30^{\circ} \mathrm{E}$ and $10^{\circ}-20^{\circ} \mathrm{N}$.

Five distinct formulations of heat measures (hereafter thermal indices) have been selected from over 100 currently existing indices (Pappenberger et al. 2015) to characterise Sahelian heatwaves (specified in Table 1). They include temperature $(\mathrm{T})$, the heat index $(\mathrm{HI})$, the Steadman non radiant Apparent Temperature (AT), the Net Effective Temperature (NET) and the Universal Thermal Comfort index (UTCI). Since this study aims at targeting the effective impacts on comfort, the criteria for the choice are essentially how they simulate the exposure of Sahelian populations to diverse extreme heat-related environmental conditions. This follows a joint WMO-WHO recommendation on heatwaves and health early warning systems (WMO-No.1142, 2015). The exposure conditions represented by the thermal indices are summarised also in Table 1. Note that they have all been used in other semi-arid regions.

For each day over the period 1979-2018, daytime and nighttime indices are derived from each thermal index. For T, HI, AT and NET, daytime (nighttime) values are obtained by combining the daily maximum (minimum) temperature and the averages over the daytime (nighttime) time steps of $09,12,15$ and 18 UTC (21, 0, 3, and 6 UTC for nighttime) of the other variables involved. The computation of UTCI is relatively complex (Bröde et al. 2012). The data are however now directly available on the ERA5 portal (Napoli et al. 2020) at an hourly resolution. For this index, the daytime (nighttime) component is taken as the maximum (minimum) over the period between 07 and 18 UTC (19 and 06 UTC), respectively, which introduces a small inconsistency with the other indices.

Considering separately the diurnal phases, there is thus a total of ten thermal indices, namely: Tday, Tnight, HIday, HInight, ATday, ATnight, NETday, NETnight, UTCIday and UTCInight. We will use these short names consistently in the paper.

\subsection{Methods for heatwave characteristics inter-comparison}

The first step in answering our two research objectives is to define a heatwave day at each data grid-cell across the Sahel. The following method is used to achieve this.

\subsubsection{Heatwave definition}

We analyse data over the months of February-June corresponding to the hot period in between the cool winter season and the monsoon season, and during which the first and most important peak of the temperature annual cycle is observed (Guichard et al. 2009; Nicholson 2018). For a given gridcell and a given thermal index several steps are followed to detect heatwaves.

First of all, from the raw data of the thermal index, we compute the 75th percentile of the total distribution and consider it as a locally fixed threshold, which will allow us to discard non-absolutely hot days.

Then considering that the synoptic to intraseasonal timescales are the most relevant for heatwaves prediction and risk management plans, the thermal index values are converted into anomaly values by removing the daily climatology (itself smoothed through a 31-day centred running averaging). These anomalies are further high-pass filtered using Lanczos weights (Duchon 1979) with a cut-off frequency of 90 days to retain variability in the synoptic and intraseasonal timescales. As data is lost at the edges of the input timeseries, the subsequent analysis is built on years 1980-2017 which are complete. From these filtered anomalies, we derive the 90th percentile value of each calendar day using a 31-day centred window to remove noise associated with a relatively short 38-year dataset.

Heatwaves are finally defined as sequences of at least three consecutive days passing both magnitude constraints simultaneously: (1) the 75th percentile of the raw data total distribution and (2) the calendar day 90th percentile of the high-pass filtered data.

Note that the calendar day threshold has been used by previous studies (e.g., Schoof et al. 2017; Perkins-Kirkpatrick and Gibson 2017).

\subsubsection{Inter-comparison of thermal index-based heatwaves at the grid-cell scale}

In order to answer research question one, we compare the statistics of heatwaves across the various thermal indices used on a gridcell basis. Specifically we analyse:

i. The heatwave duration, frequency and intensity. The duration corresponds to the length, i.e., the number of days of an event. The frequency is defined as the average number of events per year over the 1980-2017 period. The intensity is defined as the average value of the index high-pass filtered anomaly during the heatwave. To allow comparison between different indices, the intensity values are standardised (divided by their standard deviation). The results of heatwave duration, frequency and intensity are presented in map formats in Sect. 3.1.1.

ii. The 'synchronicity' of heatwave detection. For each grid-cell the binary timeseries of heatwave occurrences for different indices is compared using the coefficient of similarity or Jaccard coefficient (Jaccard 


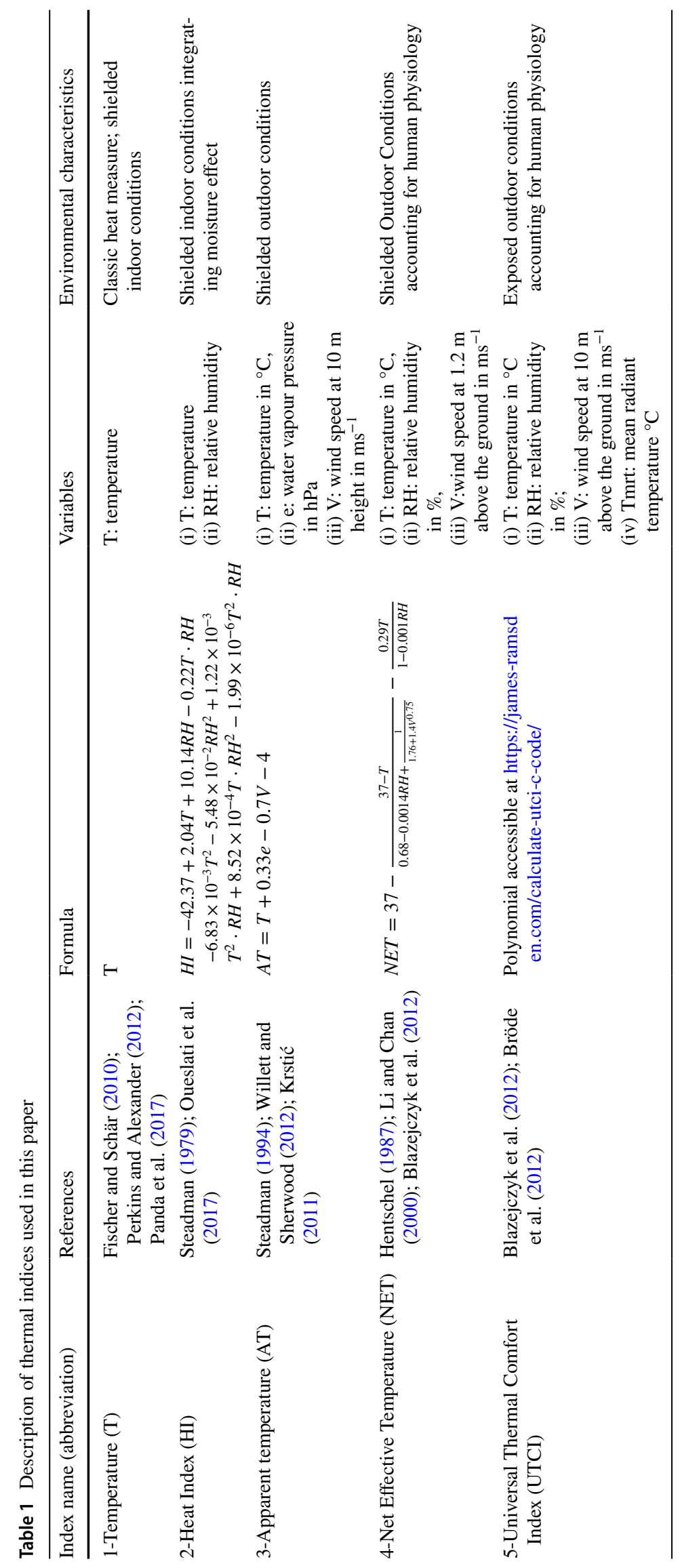


1901). Given two sets of data X and Y, the Jaccard coefficient is the ratio between their intersection and their union:

$$
J(X, Y)=\frac{X \cap Y}{X \cup Y}(1) \text { with } 0 \leq J(X, Y) \leq 1
$$

If $X=Y, J(X, Y)=1$. If $\mathrm{X}$ and $\mathrm{Y}$ have no common elements $J(X, Y)=0$.

For binary signals as in our case the formula is:

$$
J(X, Y)=\frac{M_{11}}{M_{10}+M_{01}+M_{11}}
$$

$\mathrm{M}_{00}$ : total number of attributes where both timeseries X and $\mathrm{Y}$ have a value of 0 .

$\mathrm{M}_{10}$ : total number of attributes where the attribute of $\mathrm{X}$ is 1 and the attribute of $Y 0$.

$\mathrm{M}_{01}$ : total number of attributes where the attribute of $\mathrm{X}$ is 0 and the attribute of $Y 1$.

$\mathrm{M}_{11}$ : total number of attributes where $\mathrm{X}$ and $\mathrm{Y}$ both have a value of 1 .

The results of this analysis are presented in Sect. 3.1.2.

A direct comparison between the thermal indices over all days of the February to June period (irrespective of the presence of heatwaves) is also made through computing the correlation coefficients between them. Furthermore the importance of the three main constituting variables (i.e., temperature, relative humidity and wind speed) in the thermal indices is assessed. This is done by analysing the coefficients of determination of the linear regression of each thermal index on each variable, following Berman et al. (2016). The coefficients of determination in our context are statistical measures of the portions of variances of the thermal indices attributable to the constituting variables. The diurnal phases of the variables are the same as described in Sect. 2.1, i.e. daily maximum (minimum) for temperature, and averages over the time steps $09,12,15$ and 18 UTC (21, 0, 3, and 6 UTC) for relative humidity and wind speed at daytime (nighttime). Both correlation and determination coefficients are computed at each grid-cell before spatially averaging over the Sahel domain and are presented in Sect. 3.1.3.

\subsection{Methods for understanding the thermodynamic processes underpinning heatwaves}

\subsubsection{Definition of arealy extensive large-scale heatwave events}

To address the second research objective, we analyse the thermodynamic processes only on days where major, arealy extensive, large-scale heatwave events (hereafter, LSHWs), i.e. events extending over a large number of contiguous gridcells occurred. By focussing on the LSHWs, we hope to be able to identify clear signals in the thermodynamic processes, minimising small-scale 'noise' in these data.

For each day over the February to June period, binary masks are obtained over the Sahel domain using occurrence/ non-occurrence of heatwaves at each grid-cell (grid-cell heatwaves are defined in Sect. 2.2.1 above). Then a hierarchical clustering (Anderberg 1973; Everitt et al. 2011) is applied to these grid-cells based on the spatial distances between them using the average linkage method. The ultimate aim is to identify days where LSHWs were observed. This method initially considers all grid-cells as clusters, merges the closest two, recalculates the distance between the clusters, merges again the closest two and so forth. The distance between two clusters is defined as the average distance between each grid-cell of one cluster to every grid-cell of the other cluster. The clustering process ends when the distance between the closest two clusters is larger than a subjective cut-off distance defined in this paper as $1000 \mathrm{~km}$, characteristic of the synoptic scale in meteorology. Then the areas of the clusters are calculated and only those extending over at least $600,000 \mathrm{~km}^{2}$ (consistently with Barbier et al. 2017) are considered as LSHWs. The algorithmic of this method is summarised in the supplemental material to this paper (see the flowchart in Fig. S1 and an illustration of a real case in Fig. S2).

Sensitivity tests have been carried out on both the cut-off distance (initially set to $1000 \mathrm{~km}$ ) and the minimum areal extension of the LSHWs $\left(600,000 \mathrm{~km}^{2}\right.$ initially). Reducing the latter leads to an increase of the number of events by the same order than the change of areal threshold (50\% decrease of the areal threshold leads to a doubling of the sample size) and reversely when it is increased. On the other hand, the increase of the cut-off distance between clusters leads to wider clusters and then a higher number of LSHWs. The order of the increase of the cut-off level is also conserved in terms of change of sample size (with decreasing values of cut-off level, LSHWs events become rarer). However, these changes of both areal extent thresholds and cut-off distances have no significant impacts on the spatial structures of LSHWs or the identified thermodynamic processes (see Sect. 2.3.2).

Because the minimum 3-day temporal constraint (see Sect. 2.2.1) is applied prior (at grid-cell level) to the minimum areal extent threshold (as in Schoetter et al. 2015), the LSHW event samples exclude any very fast moving events. This is consistent with our goal of detecting the likely most harmful events as we assume the longer the duration the greater the impact is. The resulting maps show the occurrence and location of LSHWs that allow the analysis of the characteristics patterns of LSHW occurrence (see Sect. 3.2) and provide the sampling basis for us to composite the fields 
of thermodynamic processes (see description in Sect. 2.3.3 and results in Sect. 3.3). For this subsequent analysis, we separate the sample of LSHW events (see Table 3) into appropriate seasons, consistent with previous work (e.g., Kalapureddy et al. 2010; Moron et al. 2018): (1) the dry season (February-March, hereafter, FM) and (2) the premonsoon season (April-June, hereafter, AMJ). The premonsoon is the hottest season of the year and obviously the most active in terms of heatwaves occurrence. The FM season stands as a transition between the coolest and the hottest seasons and carries a risk of thermal 'shocks' associated with the thermo-physiological strain of rapid adjustment (de Freitas and Grigorieva 2015a, b).

\subsubsection{Spatio-temporal partitioning of heatwaves}

We analyse the LSHW maps as follows. First, we determine the patterns of spatial variability in LSHW using an empirical orthogonal function (EOF) decomposition. These EOFs are calculated separately for each index, each season and for night and day (excluding the FM season for all nighttime indices as well as daytime indices of AT-day and HI-day, due to the small LSHW sample sizes) on all dates where a LSHW event is detected over the Sahel domain (see Table 3 for the exact input sample sizes of each index). The input data consist of the high-pass filtered anomaly values of the thermal index over the whole domain (including grid-cells which are not part of the LSHW event). Sensitivity tests of the EOF results were carried out and are discussed in Sect. 3.2.

The resulting EOF loading patterns broadly show a dipolar structure indicative of preferred occurrence of LSHW events over eastern versus western Sahel (see Sect. 3.2). On the basis of these EOF loading patterns, six characteristic heatwave types are identified (see Table 2 for the abbreviations used), accounting for the two subregions of east (E) and west (W) Sahel domains, two seasons (FM and AMJ), and the diurnal cycle of day ('d') and night ('n'). The major LSHW event days of each of the six characteristic types are identified as instances where the standardised EOF time coefficients absolutely exceed one (the sign is combined with the spatial loadings to decide whether they correspond to eastern or western Sahel). These samples of major characteristic LSHW events form the basis of the analysis of

Table 2 Heatwave types under investigation

\begin{tabular}{llll}
\hline & FM & AMJ & \\
\cline { 3 - 4 } & Day & Day & Night \\
\hline East Sahel & Ed-FM & Ed-AMJ & En-AMJ \\
West Sahel & Wd-FM & Wd-AMJ & Wn-AMJ \\
\hline
\end{tabular}

thermodynamic processes (methods described below, results in Sect. 3.2).

\subsubsection{Thermodynamic processes causing large-scale heatwave events}

To quantify the thermodynamic processes driving LSHW events, as in Oueslati et al. (2017), we derive the surface energy budget (hereafter, SEB) from ERA5 data:

$\frac{c_{s} \Delta T}{\Delta t}=S W R+L W R+S H F+L H F$

where SWR is the net shortwave radiation, LWR is the net longwave radiation, SHF is the sensible heat flux, LHF is the latent heat flux and $\mathrm{c}_{\mathrm{s}}$ is the specific heat at constant pressure of the surface. Note that the ground fluxes are neglected in this study. To assess the role of clouds during some heatwave types, the cloud radiative effect (CRE) was derived from the ERA5 data as the difference between the (longwave and shortwave) radiation of a cloud-free atmosphere and that of the real atmosphere. As a convention, the radiative fluxes are counted negatively when directed away from the surface to the atmosphere. The radiative fields are relatively well represented in ERA5 over land (Martens et al. 2020) and can thus be trusted in the present study.

The SEB considers only diabatic processes since it is derived from the first law of thermodynamics at the surface level where processes are frequently non-adiabatic. It also accounts only for the skin temperature (temperature at levels of a few centimetres high above the ground). However, people live in the boundary layer where adiabatic processes including air advection may also play an important role (e.g., Foken 2008; Leuning et al. 2012; Cuxart et al. 2015). Therefore using the $925 \mathrm{hPa}$ level as a proxy for the boundary layer, horizontal temperature advection is analysed during heatwave events to complement the SEB:

$A=-\vec{V} \vec{\nabla} T=-u \frac{\partial T}{\partial x}-v \frac{\partial T}{\partial y}$

where $\mathrm{T}$ is temperature and $\vec{V}$ is horizontal wind which is decomposed into its zonal (u) and meridional (v) components.

To account for moisture, the second most common parameter to our indices, near surface relative humidity data are investigated. Cloud cover data are also examined to help describing the synoptic conditions during heatwaves.

Similarly to the thermal indices, all the physical quantities are first high-pass filtered to retain variability at the synoptic and intraseasonal scales (see Sect. 2.1). Their composite mean anomalies for the major LSHW event days and preceding days were derived for each of the six LSHW types. The statistical significance at the 0.05 probability level of each 
composite mean departure from zero was determined by a Student's $t$ test. These anomalies are standardised and the magnitude of the anomalies indicates their likely contribution to causing the heatwave.

To compare the magnitude of the thermodynamic processes driving various heatwave indices directly, they are spatially averaged over grid-cells where the EOF spatial coefficient has a normalised amplitude larger than 0.3 (results shown in Sect. 3.3).

\section{Results}

\subsection{Heatwave characteristics and statistics across thermal indices}

\subsubsection{Heatwave characterization}

We assess the three most important measures of heatwaves: Duration, frequency and intensity (defined in Sect. 2.2.2). In terms of duration (Figs. 1a and 2a) we see that:

(i) Sahel heatwaves are typically not especially long lasting, with a mean duration not much in excess of the 3-day minimum threshold and with little apparent sensitivity to the various thermal indices. Overall, the mean duration is quite low compared to other regions (e.g., Australia, Cowan et al. 2014) and other definitions over the Sahel (Oueslati et al. 2017; Barbier et al. 2017). However, the longest lasting daytime heatwaves on record (Fig. S3.a and S4.a) persist for up to two weeks over some locations (central Burkina Faso, Northwestern Nigeria and across the ChadNiger border).

(ii) Daytime events are longer lasting than nocturnal events (Figs. 1a vs 2a) persisting on average up to 4.5 days (Fig. 2a) notably over the Central Sahel.

(iii) Although the spatial variability in duration is not pronounced, broadly the Central and East Sahel experiences longer lasting events than the West during both day and night across most indices (Fig. 1a and 2a).

(iv) Across the thermal indices, although differences are relatively small, over Eastern Sahel, AT presents the longest events at night (AT-night but has some of the shortest events during the day (AT-day). This may be caused by the strong diurnal cycle of wind speed and its 'cooling' effect in the AT index formulae (Table 1). Surface wind speeds are highest during the day when boundary layer mixing is greatest and lowest at night when surface-atmosphere decoupling is pronounced and nocturnal low level jets commonly form Parker et al. (2005), Washington and Todd (2005) and Fiedler et al. (2013). (a) Duration
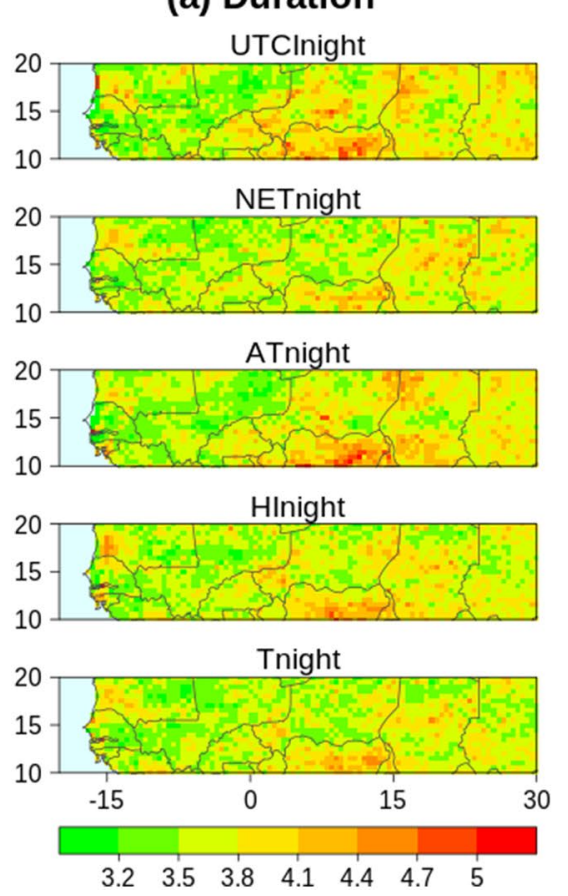

(b) Intensity
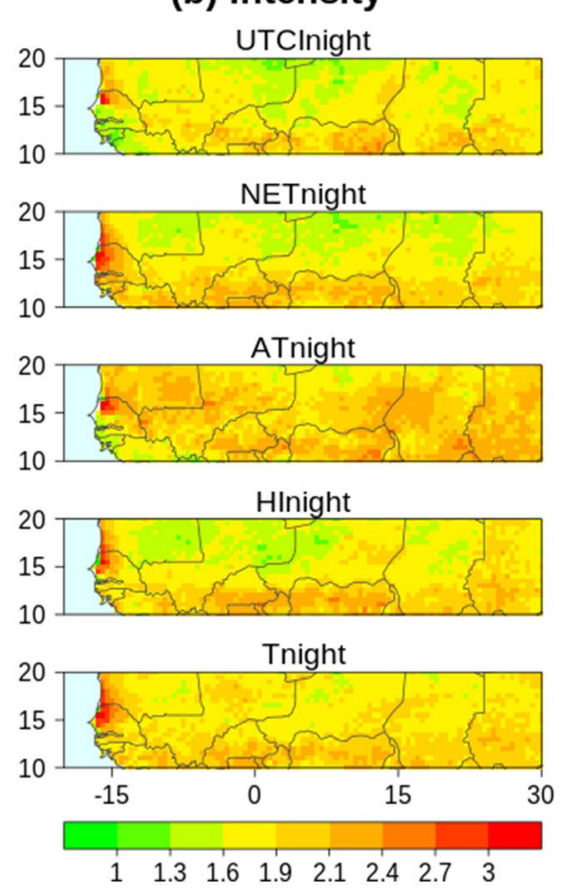

(c) Frequency

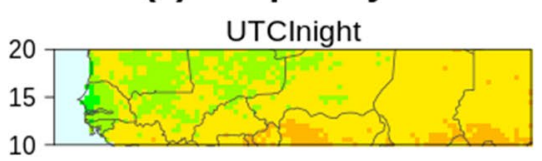

NETnight

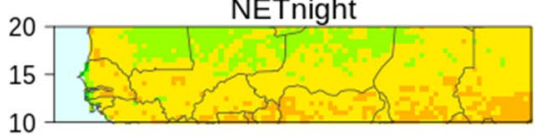

ATnight
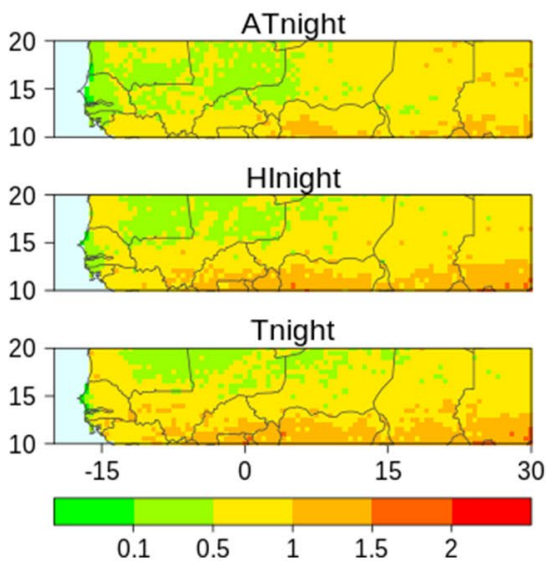

Fig. 1 Characteristics of nighttime heatwaves: a average duration in number of days per event, $\mathbf{b}$ average intensity in standardised units and $\mathbf{c}$ frequency in number of events per year. See Sect. 2.2.2 for the computation method 
(a) Duration
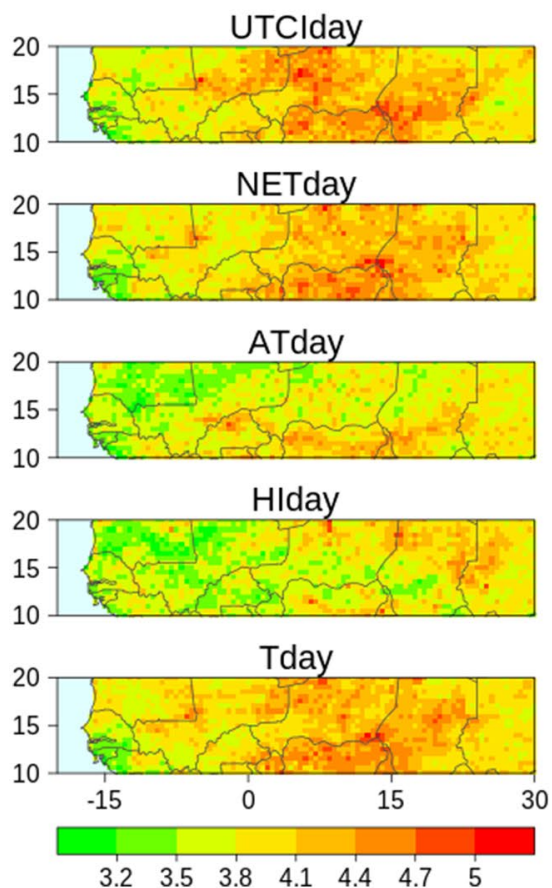

(b) Intensity
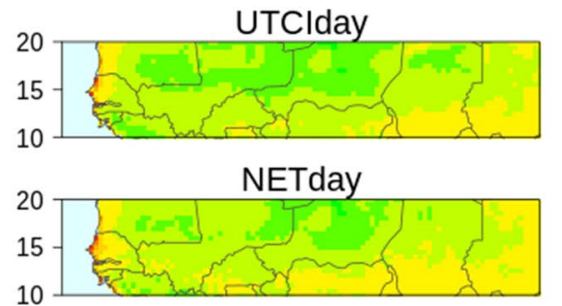

ATday
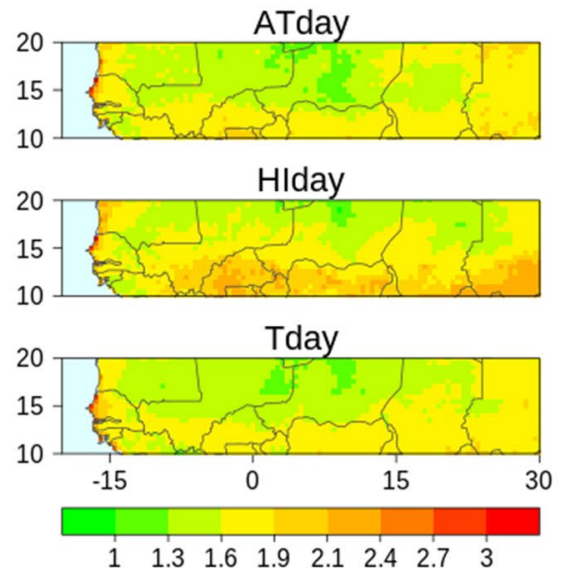

(c) Frequency

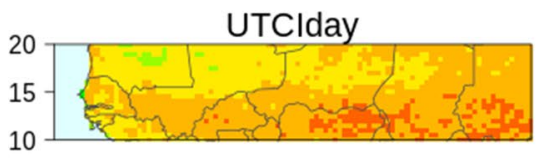

NETday

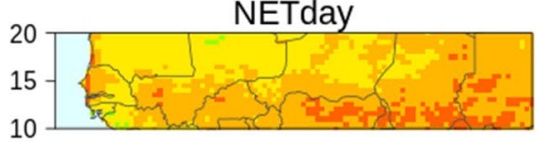

ATday
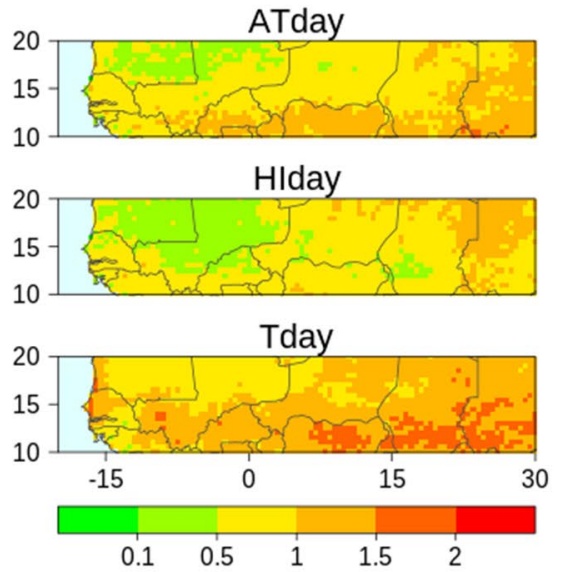

Fig. 2 Same as Fig. 1 but for daytime heatwaves

Regarding heatwave intensity we note that:

(i) Nighttime events are slightly more intense than daytime (the magnitude of the differences between them is mostly below 0.3 standard deviation) (Fig. $1 \mathrm{~b}$ vs 2b).

(ii) There is a higher intensity in the East, the extreme West and the southernmost parts (Soudan belt) of the Sahel compared to the Centre for most indices.

(iii) There is considerable variability in intensity with the most extreme events exceeding 5 (3) standard deviations in the eastern (western) Sahel (Fig. S3b and S4b). Such events are likely to be very harmful in terms of health.

Regarding heatwave frequency, most grid-cells experience between one and two events per year (Figs. 1c and 2c), with increasing values from West to East Sahel, for both day and night events - a similar structure to that of duration and intensity. Daytime events are slightly more frequent than nighttime events.

These contrasts in the diurnal cycle and the spatial distribution are mostly explained by the constraints of the heatwave definition and the spatio-temporal variability of the thermal indices. A sensitivity test on the minimum duration constraint reveals that extreme hot events persist longer in daytime than nighttime over the dry East Sahel whereas over the West nighttime heatwaves last longer.

The locally fixed intensity threshold (75th percentile of the total distribution of the raw indices) also amplifies the day/night and East/West disparities through highlighting the differential annual cycle. The distributions of indices during the nighttime and over and the western Sahel are more clustered around the average values (Fig. S5 and S6) resulting in lesser heatwave probabilities especially during transitional months (February and March). In fact, for most indices (UTCI being the exception), the variances are larger during the daytime and over the East than at nighttime and over West Sahel (Fig. S7).

It should also be noted that the 75th percentile of the total distribution is very determinant in ensuring that the intraseasonal events that are detected are hot indeed. March is a transition month in the Sahel and without this constraint most heatwaves would have been detected in this month given its strong intraseasonal variability.

In summary, the statistics show eastern Sahel (especially Chad and Sudan) to be the most affected by heatwaves, hosting the longest lasting, most intense and most frequent events. Heatwaves are more frequent and longer-lasting during daytime compared to nighttime, while there is little diurnal difference in intensities. For the same diurnal period, the differences in heatwave statistics between indices are not especially important. 


\subsubsection{Synchronicity of heatwaves defined by the various thermal indices}

The previous section suggests that the choice of thermal index does not affect greatly the characteristics and basic statistics of the heatwaves detected. However, does this mean the indices identify the same events? Our analysis of the Jaccard coefficient of similarity suggests quite surprising results. The average Jaccard coefficient (i.e. the average Jaccard coefficient for a given thermal index versus the other four indices for nighttime (Fig. 3a) and daytime (Fig. 3b) separately is typically less than 0.5 across the vast majority of domain grid-cells. No clear spatial consistency is observed in the similarity index patterns across the pairs of indices although the northeast of the domain centred on the Chad-Sudan border repeatedly depicts the maximum similarity between indices. Even for the most similar two indices the Jaccard coefficients are only quite moderate with almost all the domain experiencing values less than 0.7 during the day, and lower for nighttime. The probable reasons for this dissimilarity are discussed in Sect. 3.1.3 and in Sect. 4 we discuss the potential implications for heatwaves risk managements in the Sahel.

The similarity between day and nighttime events is lower still (Fig. 4c) with typically less than $10 \%$ of all heatwave days being common to both day and night for most indices and grid-cells. The HI index has the greatest similarity across day and night such that daily average of this index would yield the most robust combined indicator. So in the Sahel, daytime and nighttime heatwaves do not usually occur simultaneously, a finding consistent with Barbier et al. (2017). This also has profound implications which are explored in Sect. 4.

\subsubsection{Factors of the low co-occurrence across heatwaves samples}

In this section, the reason for the low Jaccard coefficients between heatwaves sampled from different indices over the same diurnal phase (Fig. 3a, b) is investigated. Two main factors could be seen to exert a control on the coincidence of heatwaves sample from different indices: (1) the upstream constraints imposed on heatwave definition (duration and intensity thresholds) and (2) the interaction between the constituting variables of the thermal indices.

A sensitivity analysis on the impact of the duration, absolute and calendar day thresholds is presented in Fig. 4 using Tday as an example (the rates of the changes are similar for the other heatwave indices). Thus lowering the magnitude thresholds induces an increase of the Jaccard coefficient between the heatwave samples. As an illustration, the average Sahel-wide Jaccard coefficient between Tday and the four other daytime heatwave indices is approximately 1.5 times higher if the calendar day threshold is set to the $50^{\text {th }}$ (a) Nighttime
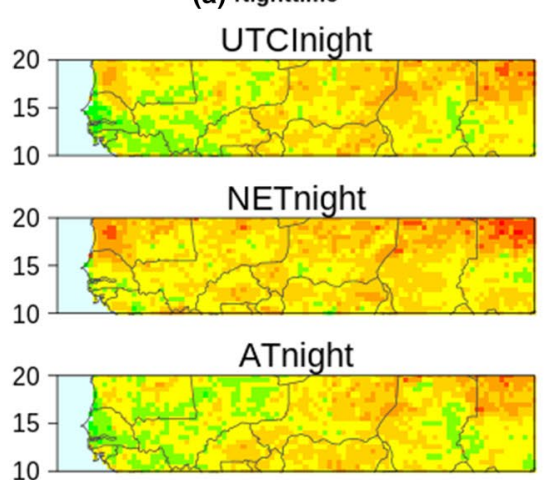

HInight
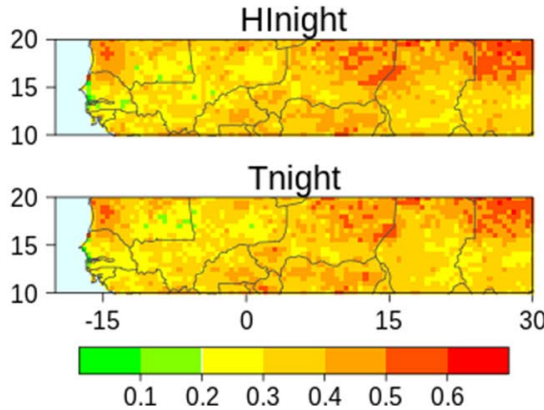

(b) Daytime

UTClday

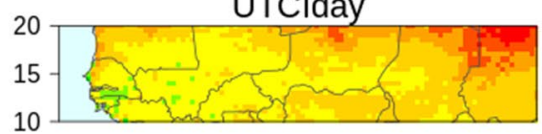

NETday

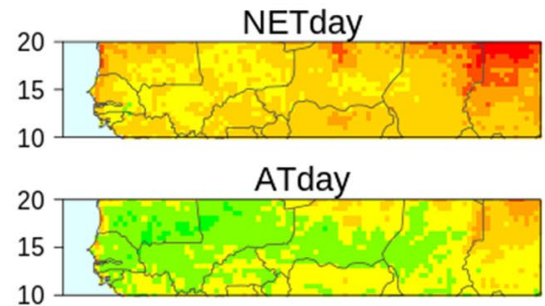

HIday

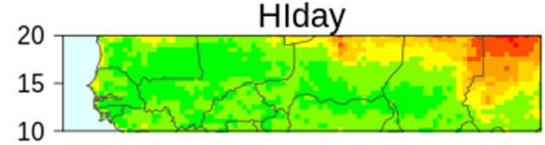

Tday

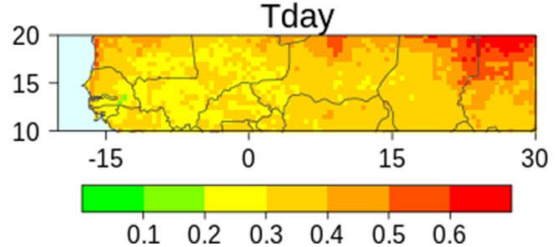

(c) day vs night

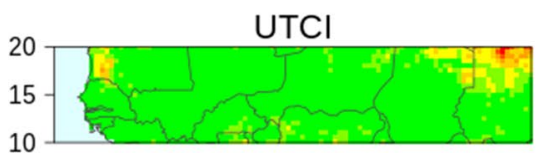

NET

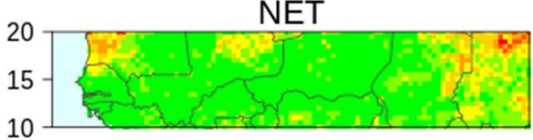

AT

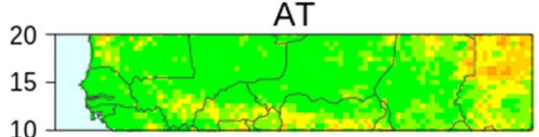

$\mathrm{HI}$

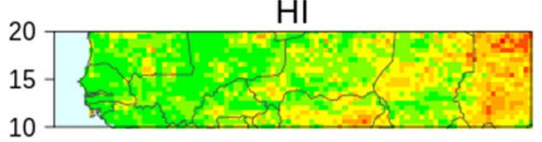

$\mathrm{T}$

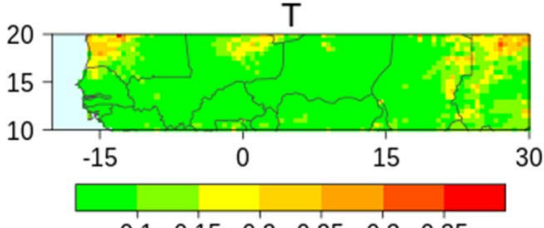

$\begin{array}{llllll}0.1 & 0.15 & 0.2 & 0.25 & 0.3 & 0.35\end{array}$

Fig. 3 Average Jaccard similarity coefficients between each thermal index and the other four of the same diurnal phase at $\mathbf{a}$ nighttime and $\mathbf{b}$ daytime, and $\mathbf{c}$ between the daytime and the nighttime components of the same index 
Fig. 4 Sensitivity of Sahel-wide average Jaccard coefficients between T-day and the four other daytime heatwave indices (HI-day, AT-day, NET-day and UTCI-day) to changes of heatwave definition thresholds. The red line represents averages of the Jaccard coefficients when the relative threshold is varied between the 90th and the 50th percentile of calendar day distribution (keeping the absolute threshold to 75th percentile of the total distribution and the minimum duration to three days); likewise for the blue (green) lines but changing the absolute threshold and keeping the calendar day threshold to the 90th percentile and the duration to three days (changing the duration between five days and one day and keeping the relative threshold to the 90th percentile of calendar distribution and the absolute threshold to the 75th percentile of the total distribution)

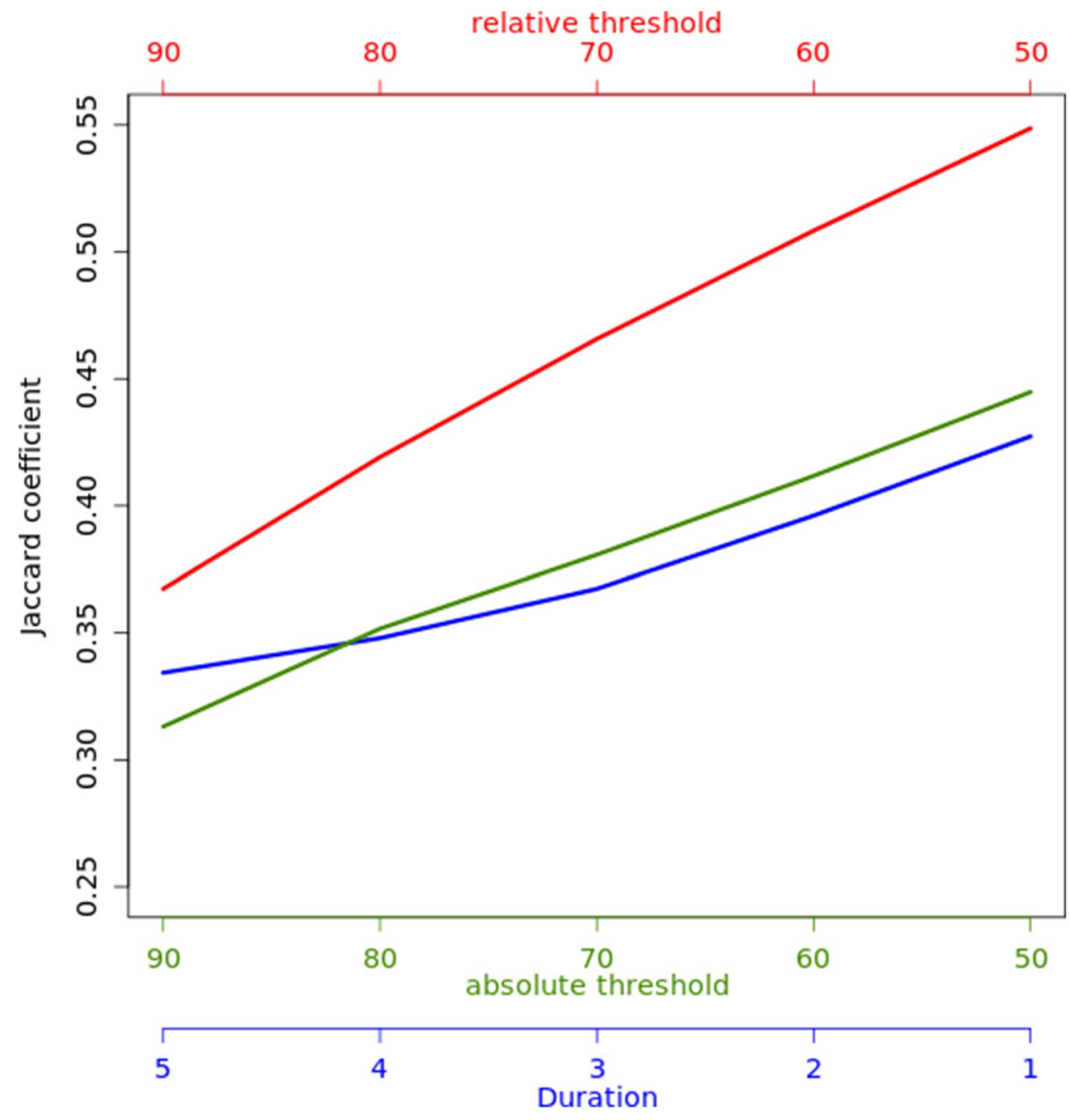

percentile rather than the 90th percentile (without changing the other constraints). Similar (but slightly lower) variations are observed for the absolute intensity threshold. The coincidence between heatwave samples also increases with decreasing heatwave duration thresholds. There is indeed an average increase (Sahel-wide) of 0.04 of the Jaccard coefficient when the duration threshold is shortened by a day. This means that, if at the outset the minimum duration was set to two consecutive days, the absolute intensity threshold to the 60th percentile of the total distribution and the relative intensity threshold to the 80th percentile of calendar day distribution, the average Jaccard coefficient of Tday would have been 0.5 instead of 0.36 (not shown). Consequently the more extreme the constraints for heatwave detection, the lower the co-occurrence of heatwave events across different thermal indices. Note that the variation of the different thresholds does not affect the spatial patterns of the Jaccard coefficients illustrated in Fig. 3.

The correlation coefficients between the thermal indices are relatively high (black solid lines in Fig. S8) but the proportions of the thermal indices variance explained by temperature, relative humidity and wind speed (method described in Sect. 2.2.2) varies significantly from an index to another and also contributes to the low inter-indices Jaccard coefficients, especially during the AMJ season. Out of these constituents, wind speed (green dashed lines in Fig. S8) is generally the least important to the indices variance. It however shows a relatively important portion of explained variability during the dry season (FM) where its annual cycle is at its peak with daytime more affected than nighttime. The daytime components of AT and UTCI are the most impacted by wind speed. Wind almost has no impact on HI, and therefore with increasing ventilation, a moist and hot air is more likely to lead to an HI-heatwave.

Since all indices have temperature as their principal variable (Table 1), it explains most of their variance (above $80 \%$ in most indices, red dashed lines in Fig. S8). However its importance varies with the season, the diurnal cycle and the indices themselves. In FM, the influence of temperature is the largest and slightly decreases gradually in AMJ as the role of relative humidity (blue dashed lines in Fig. S8) increases due to moisture surges (Couvreux et al. 2010). It 
Fig. 5 Leading EOF loadings for different LSHW types using the $\mathrm{T}$ index. Numbers in brackets are the portions of variance explained (see Sect. 2.3.2 for the method description)
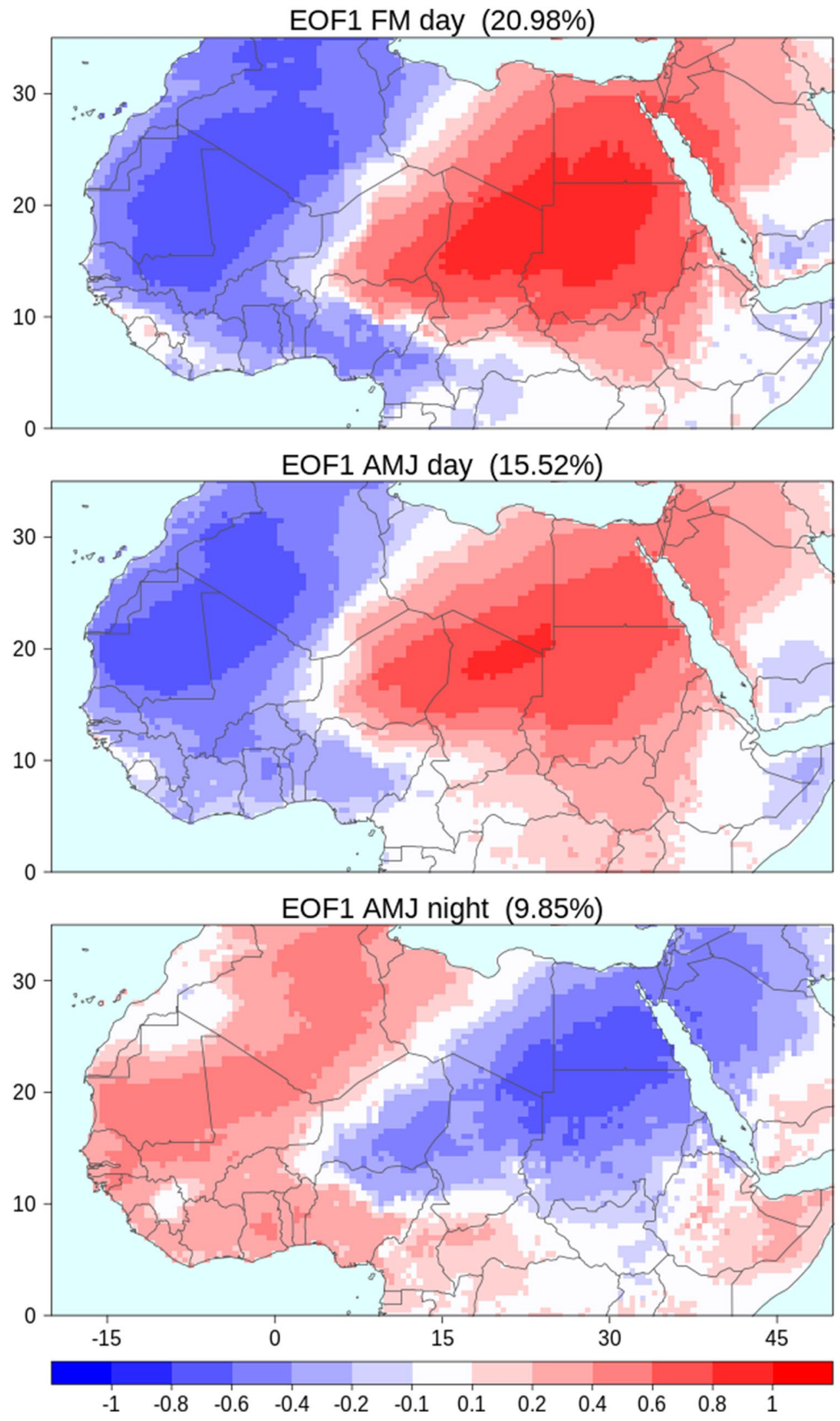
Table 3 Sample sizes of daytime and nighttime LSHWs over the 1980-2017 period

\begin{tabular}{|c|c|c|c|c|c|c|c|c|c|c|}
\hline & \multicolumn{2}{|l|}{$\mathrm{T}$} & \multicolumn{2}{|l|}{ HI } & \multicolumn{2}{|l|}{ AT } & \multicolumn{2}{|l|}{ NET } & \multicolumn{2}{|l|}{ UTCI } \\
\hline & Night & Day & Night & Day & Night & Day & Night & Day & Night & Day \\
\hline $\mathrm{Feb}$ & 7 & 43 & 0 & 6 & 0 & 7 & 10 & 41 & 0 & 19 \\
\hline Mar & 49 & 160 & 33 & 34 & 9 & 70 & 66 & 162 & 6 & 134 \\
\hline Apr & 182 & 238 & 163 & 169 & 105 & 222 & 183 & 235 & 113 & 247 \\
\hline May & 224 & 202 & 212 & 199 & 204 & 212 & 190 & 191 & 217 & 208 \\
\hline Jun & 137 & 128 & 136 & 124 & 116 & 150 & 137 & 134 & 139 & 164 \\
\hline FM & 56 & 203 & 33 & 40 & 9 & 77 & 76 & 203 & 6 & 153 \\
\hline AMJ & 543 & 568 & 511 & 492 & 425 & 584 & 510 & 560 & 469 & 619 \\
\hline Total & 599 & 771 & 544 & 532 & 434 & 661 & 586 & 763 & 475 & 772 \\
\hline
\end{tabular}

should be noted that temperature itself is strongly associated with moisture in AMJ at daytime (due to clouds; Fig. S8b). Consequently, an anomalously clearer (cloudier) sky than usual increases (decreases) the probability of T-day heatwaves (the same conclusion cannot be straightforwardly drawn for HI, AT and UTCI heatwaves probabilities as shown below). NET is the index with the strongest links with temperature especially at daytime with the coefficient of determination close to 1 (Fig S8h), leading to high Jaccard coefficients between T-day and NET-day. The thermal indices with the weakest links with temperature are HI-day, AT-day, AT-night and UTCI-night (Fig. S8d, S8f, S8e and $\mathrm{S} 8 \mathrm{i}$ respectively). The causes are not the same however. For HI-day and AT-day, it is due to the opposed daytime evolution of temperature versus moisture (Gounou et al. 2012): an increase of moisture may be associated with an increase of clouds (e.g., mid-level altocumulus, Bourgeois et al. 2018) and thus cause a decrease of temperature. For AT-night and UTCI-night, wind speed although with low determination coefficients, tends to counteract both the moisture and temperature effects. UTCI-day on the other hand maintains a relatively important link with temperature given that it takes solar radiation into account in its formulation, the latter being itself well correlated with temperature (Blazejczyk et al. 2012).

Summarily the choice of various constraints for heatwave definition and the interaction between the constituting variables of thermal indices are two important factors for the (a) synchronicity of heatwaves samples. The second factor also affects the underpinning thermodynamic causes as will be described in Sect. 3.3.

\subsection{Thermodynamic processes: spatial structures of Sahelian heatwaves}

From this section, the focus is on large scale heatwave (LSHW) events as defined in Sect. 2.3.1. Table 3 presents the input sample sizes of each index for each month and season of interest over the 1980-2017 period. T (HI) has the largest (smallest) sample size. Regarding the temporal distribution, the smallest heatwave sample is recorded in February across all indices, mainly as a consequence of the absolute threshold ( 75 th percentile). The months with the largest heatwave occurrences are April for the daytime (except HI-day) and May for the nighttime (Table 3).

The spatial structures of variability associated with LSHWs are assessed through an EOF analysis (see Sect. 2.3.2). To ensure robust results we test the sensitivity of the technique to the sampling domain (Hannachi et al. 2007), by using two imbricated regions consistent with Richman (1986): A small domain covering the Sahel only $\left(20^{\circ} \mathrm{W}-30^{\circ} \mathrm{E}\right.$ and $\left.10^{\circ}-20^{\circ} \mathrm{N}\right)$ and a larger domain extending over the entire Northern Africa domain $\left(20^{\circ} \mathrm{W}-50^{\circ} \mathrm{E}\right.$ and $0^{\circ}-35^{\circ} \mathrm{N}$ ). The resulting EOF loading patterns are very similar within their overlapping area and we use only the larger domain for further analyses since the EOF loadings of the smaller domain peak towards the boundaries of the Sahel box suggesting processes of larger spatial scale. The EOF loading patterns are also insensitive to the choice of minimum areal threshold or cut-off distance (see Sect. 2.3.1).

Our results indicate that the leading mode of each heatwave type, which explains around $15 \%$ of the total variance, has a zonally dipolar structure (Fig. 5, illustrated using the results from the $\mathrm{T}$ index). This means that $\mathrm{LSHW}$ events over western (eastern) Sahel are associated with relative cooling (warming) in eastern (western) Sahel. Note that the temperature anomalies associated with several weather type patterns over the northern tropical Africa domain also present the dipolar structure (Moron et al. 2018). The percentages of variance of LSHWs explained by the EOFs are relatively low but the method in itself is a robust and objective approach to capture the natural patterns of variability and has been extensively used in climate studies (e.g., Hannachi et al. 2006).

\subsection{Thermodynamic processes: energy budget and moisture analyses}

In this section, we assess the underlying thermodynamics associated with each heatwave type using the terms of the 

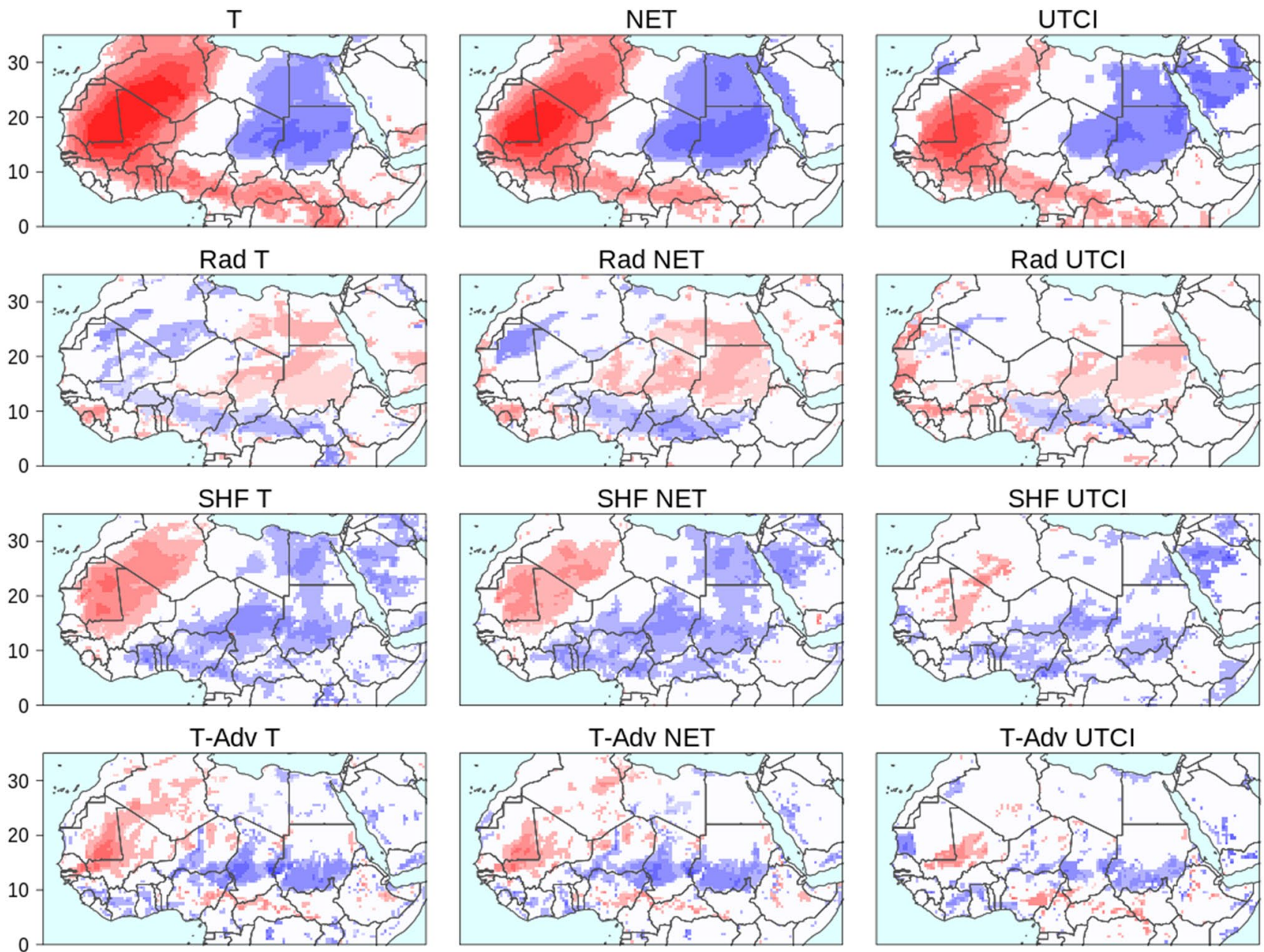

$\mathrm{RH} \mathrm{T}$

RH NET
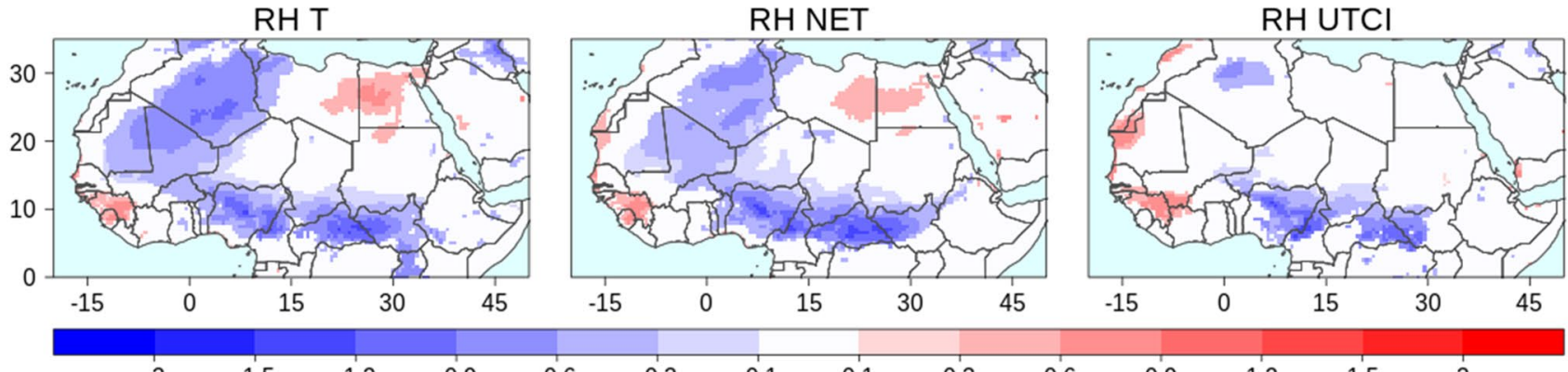

Fig. 6 Normalised anomalies associated with heatwaves occurring over Western Sahel at daytime during the FM season (Wd-FM). The top panel shows the anomalies of the indices themselves and the subsequent panels the anomalies of net radiation ( $\mathrm{Rad}$ ), sensible heat flux (SHF), temperature advection (T-Adv) and near surface relative

humidity (RH) in that order. Shown from left to right are the anomalies associated with heatwaves detected using T, NET and UTCI respectively. White areas are not significant at the 0.05 probability level

surface energy budget (Eq. 3) and the heat advection (Eq. 4) presented in Sect. 2.3.3. Before describing the details of each heatwave type, it is important to mention some general observations. All heatwave types are associated with an increase of temperature and most of them see a significant decrease of wind speed. In terms of magnitude, Eastern Sahel heatwaves processes are generally larger than their

Western Sahel counterparts. Similarly, in FM the magnitude of the processes are more important than in AMJ in agreement with Moron et al. (2018). The analysis of the SEB on days leading to the heatwave reveals that for most heatwave types the anomalies of the processes keep the same sign as during the heatwave or are null. A progressive increase of their magnitude is however observed towards the onset of 
the heatwaves (except during the FM season), meaning that the heating is not sudden but is a gradual process.

Latent heat flux is generally the least important of the SEB terms with relatively small anomalies, hence its omission hereafter.

For conciseness purposes, to indicate the origins of hot air in cases where heat advection is important, only wind anomalies associated with $\mathrm{T}$ are shown (Fig. 12).

The key results presented by heatwave type in the following discussion are summarised in Table 4 where information on the diagnostic and leading processes as well as the agreement between the indices is presented.

Daytime heatwaves in the FM season over Western Sahel (Wd-FM) Fig. 6 They are characterised by a decrease of surface relative humidity and cloudiness for T and NET and reversely for UTCI. Regarding the underlying processes, $\mathrm{T}$ and NET agree on the leading role of heat advection centred near the border between Mali and Mauritania and originating from the region southeast to the heatwave area (i.e. Burkina Faso and Western Niger; Fig. 12a). As shown in Fig. S9, the advection initiates up to three days prior to the heatwave and peaks the day before the onset with an intensity above 0.3 standard deviation. During UTCI events the intensity of temperature advection is less important (less than 0.2). However the presence of low level moisture favours a gain of thermal radiation amounting to around 0.1 that also contributes to the warming.

Daytime heatwaves in the FM season over Eastern Sahel (Ed-FM): Fig. 7. The characteristics of these events are consistent across the thermal indices. They are associated with a dipole of low level moisture anomalies with the Eastern Sahel (i.e. the heatwave region) hosting dryer air.
There is also an increase of cloud cover whose structure has a southwest-northeast (SW-NE) orientation from the gulf of Guinea toward Eastern Sahara (not shown). An important decrease of surface wind speed is also observed (the FM season corresponds to the annual peak of wind speed over the region, Guichard et al 2009). The leading thermodynamic process is (consistently across all indices) hot air advection from the equatorial West Africa to the Eastern Sahel/Sahara (Fig. 12b). It starts up to five days before the heatwave (Fig. S9), increases gradually and reaches its maximum the day before the onset. It also leads to the surface sensible heat flux anomaly turning positive (as per our convention this means less flux from the ground into the atmosphere). A particularity of this heatwave type is that, compared to the others, it is associated with large anomalies especially of temperature (in excess of two standard deviations), wind speed (absolutely above 0.5 standard deviation), advection (above 0.5 standard deviation) and sensible flux (close to one standard deviation). The surface shortwave radiation follows the cloudiness pattern with negative anomalies oriented SW-NE from the Guinean countries through central Sahel to Eastern Sahara. As for the longwave anomalies they match the low level moisture, depicting a dipolar structure with radiative loss over the heatwave region.

Daytime heatwaves over western Sahel in AMJ (Wd$A M J)$ : Fig. 8. These events extend over a broad sector from the countries of the gulf of Guinea to Western Sahara, centred in northern Mali. They are consistently accompanied by a decrease of moisture and cloudiness (Fig. S10) over the region of interest. The decrease is the most important for $\mathrm{T}$ and NET. At the exception of AT, all heatwave indices show

Table 4 Degree of agreement between the indices and diagnostic and major thermodynamic processes for each heatwave type

\begin{tabular}{lll}
\hline $\begin{array}{l}\text { HW type } \\
\text { (Degree of agreement between the indices) }\end{array}$ & Diagnostic & Thermodynamic causes \\
\hline $\begin{array}{l}\text { West day FM } \\
\text { (Fair agreement) }\end{array}$ & $\begin{array}{c}\text { Decrease (increase) of moisture for T and NET } \\
\text { (UTCI) }\end{array}$ & $\begin{array}{c}\text {-Heat advection (T and NET) } \\
\text {-Heat advection and LW (UTCI) }\end{array}$ \\
$\begin{array}{ll}\text { East day FM } \\
\text { (Large agreement) }\end{array}$ & -Dipole of moisture (dry in the HW region), \\
weaker winds & Heat advection \\
West day AMJ & Decrease of moisture and cloudiness in all & -Heat advection in the north and sensible flux in \\
(Fair agreement) & indices & the south in T, AT, NET, UTCI \\
& Increase of wind speed except in AT & -Shortwave radiation in the north and sensible \\
& flux in the south in HI \\
East day AMJ & -Decrease of moisture and cloudiness in T, NET, & Heat advection \\
(Fair agreement on the diagnostic, large & UTCI & \\
agreement on the thermodynamic causes) & -Reversely in HI, AT & \\
West night AMJ & -Increase of wind speed and cloud cover, small & -Small LW (T, HI, NET) \\
(Fair agreement) & decrease of moisture in T, HI, NET & -LW, sensible flux and heat advection (AT, \\
& -Decrease of wind speed, increase of moisture in & UTCI) \\
East night AMJ & AT, UTCI & \\
(Large agreement) & Increase of moisture and cloudiness, decrease of & LW (primarily) and sensible flux \\
\hline
\end{tabular}



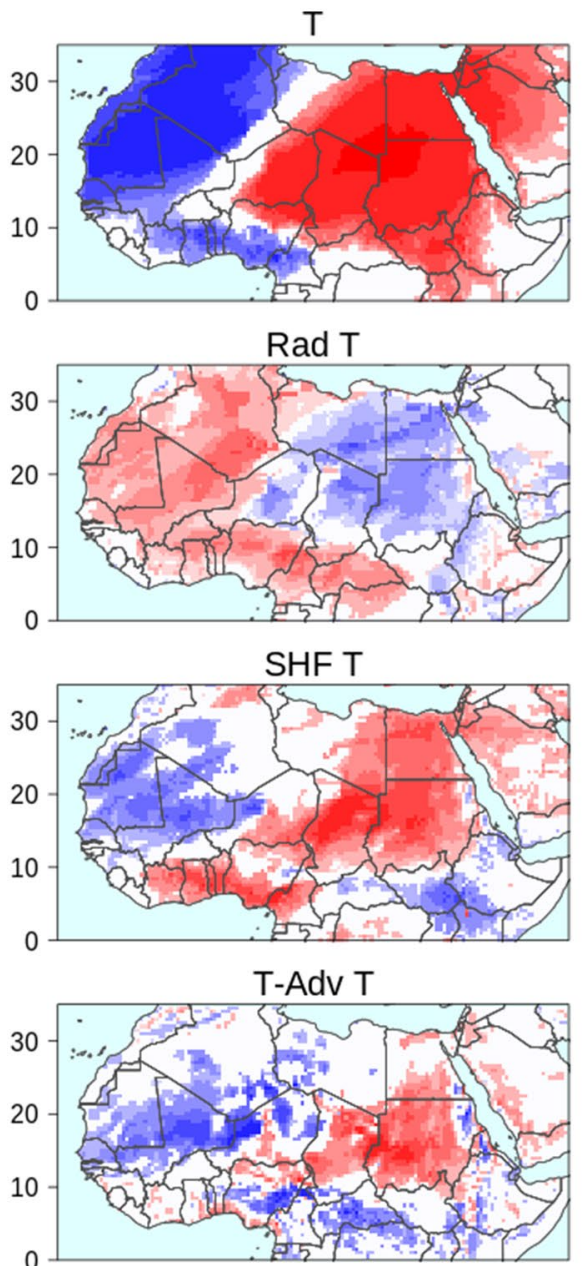

$\mathrm{RH} \mathrm{T}$

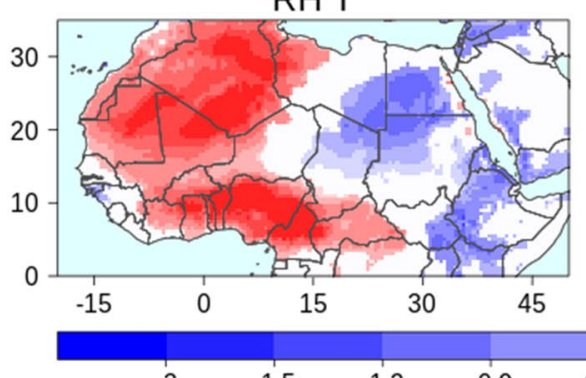

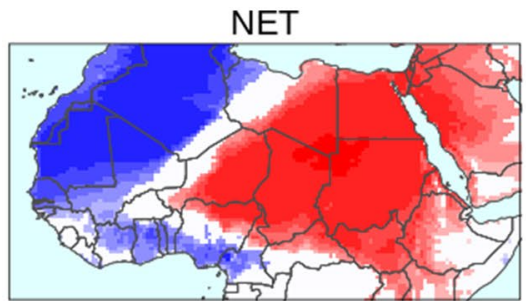
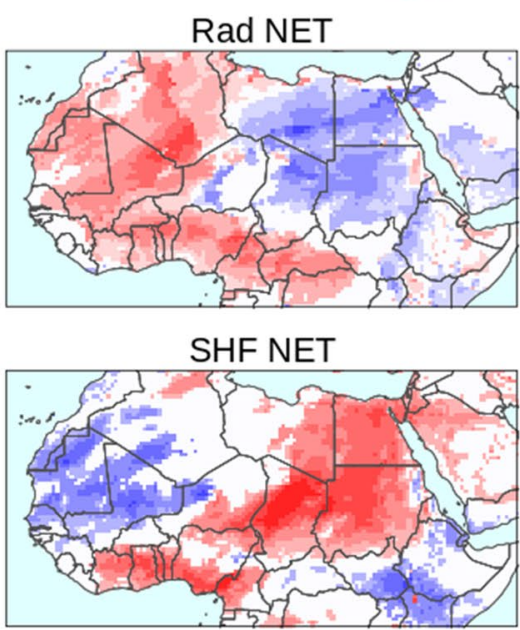

T-Adv NET

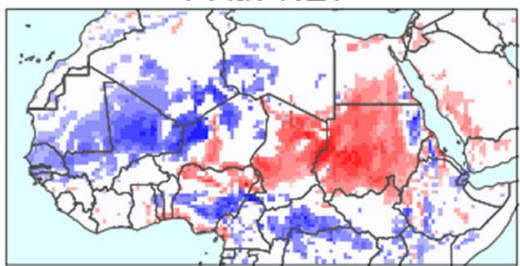

RH NET

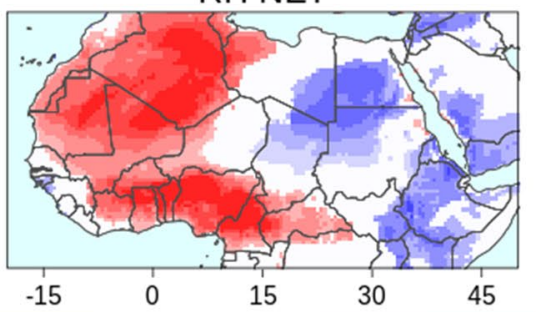

0.6
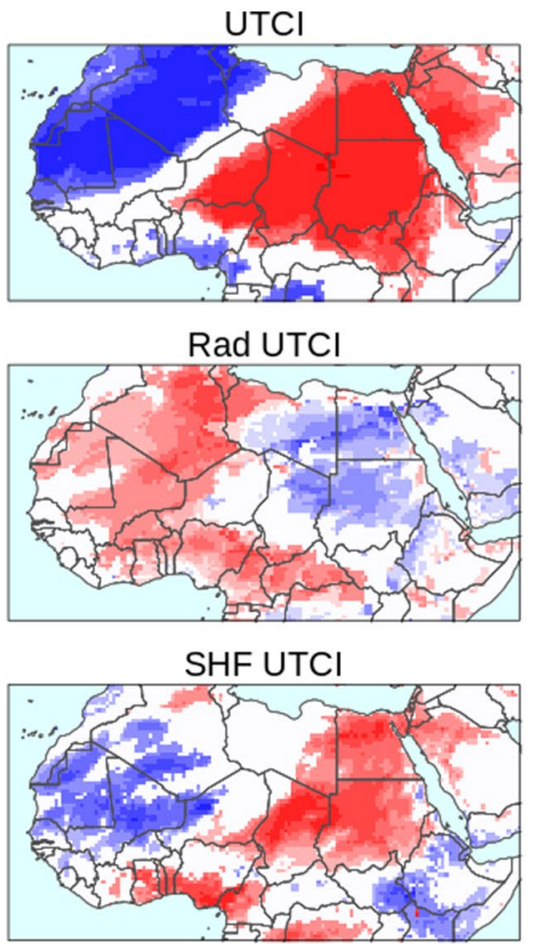

T-Adv UTCI

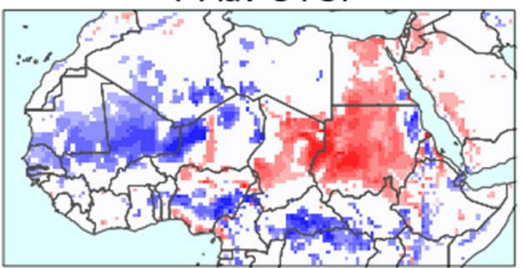

$\mathrm{RH}$ UTCl

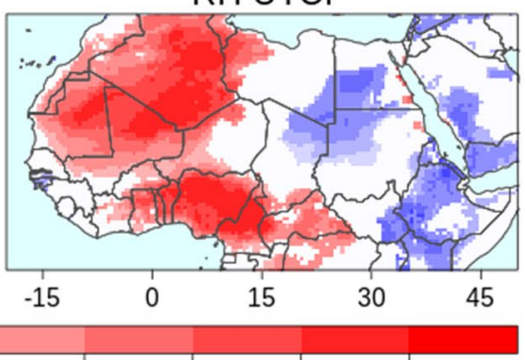

Fig. 7 Same as Fig. 6 but for heatwaves occurring over Eastern Sahel at daytime during the FM season (Ed-FM)

an increase of the surface ventilation (Fig. S10, consistent with Sect. 3.1.3).

The thermodynamic causes differ between the northern (Mauritania) and the southern (Burkina Faso, southern Mali) parts of the heatwave region. In the northern part, four out of five indices (T, AT, NET and UTCI) point to advection of hot air (with magnitude around 0.2 standard deviation) from the area near the Algeria-Mali-Niger trijunction as cause of the heating. In HI events the increase of incident solar radiation (following the decrease of cloudiness) stands as the leading cause of the heatwave in front of heat advection.

In the southern part of the heatwave region, all indices concord on an increase of sensible heat flux from the soil into the atmosphere as the process responsible for the heating. This process also extends to the Guinean band.

Daytime heatwaves over eastern Sahel in AMJ (Ed-AMJ): Fig. 9. These heatwaves extend over a broad sector of eastern Sahel and appear to be an extension of heatwaves centred 


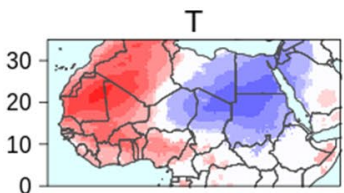

$\operatorname{Rad} \mathrm{T}$

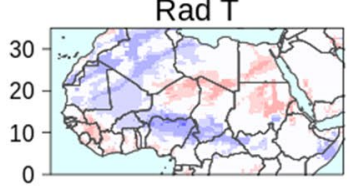

SHF T

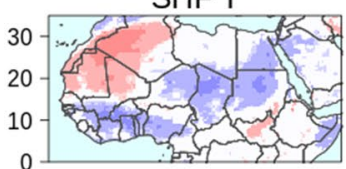

T-Adv T

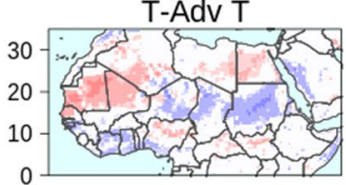

$\mathrm{RH} \mathrm{T}$

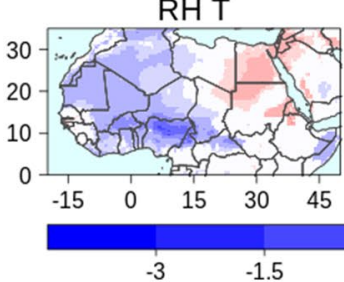

$-3$

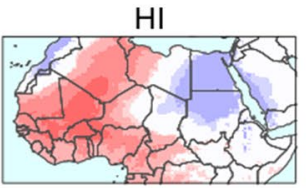

$\mathrm{Rad} \mathrm{HI}$

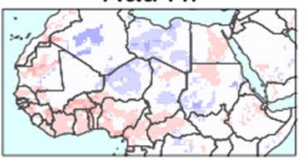

SHF HI

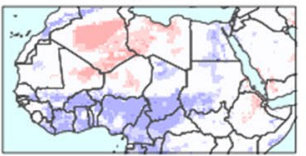

T-Adv HI

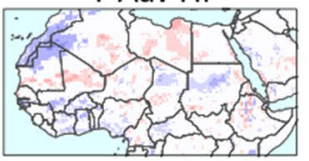

$\mathrm{RH} \mathrm{HI}$

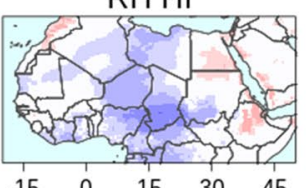

$\begin{array}{lllll}-15 & 0 & 15 & 30 & 45\end{array}$

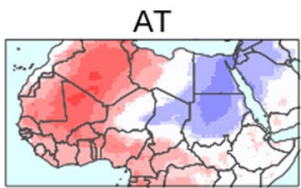

Rad AT

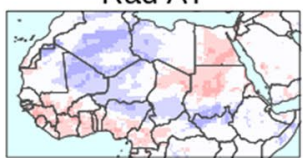

SHF AT

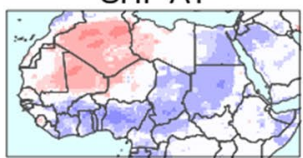

T-Adv AT

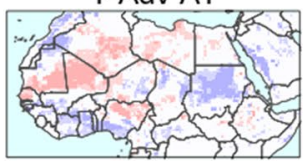

RH AT

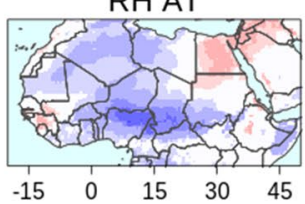

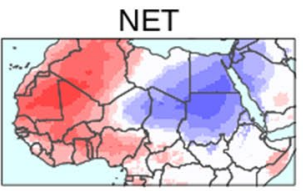

Rad NET

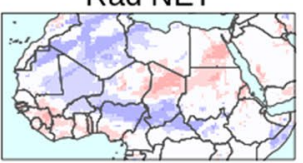

SHF NET

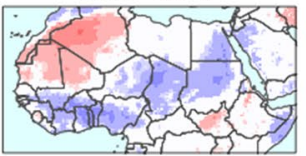

T-Adv NET

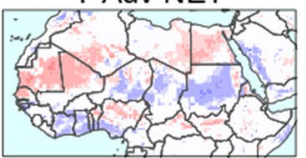

RH NET

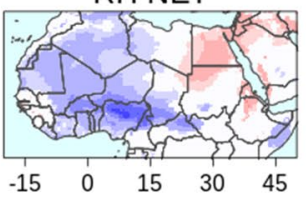

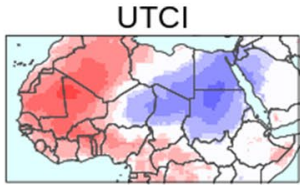

Rad UTC

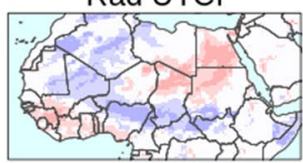

SHF UTCI

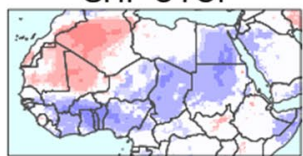

T-Adv UTCI

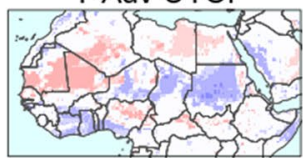

$\mathrm{RH} \cup T C$

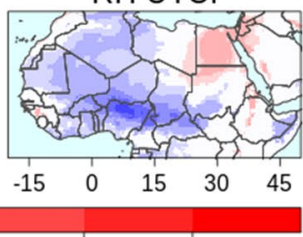

Fig. 8 Normalised anomalies associated with heatwaves occurring over Western Sahel at daytime during the AMJ season (Wd-AMJ). The top panel shows the anomalies of the indices themselves and the subsequent panels the anomalies of net radiation (Rad), sensible heat flux (SHF), temperature advection (T-Adv) and near surface relative humidity $(\mathrm{RH})$ in that order. Shown from left to right are the anomalies associated with heatwaves detected using T, HI, AT, NET and UTCI respectively. White areas are not significant at the 0.05 probability level

but the dryness of the low level atmosphere also lets more thermal radiation out. On the other hand, there is less incoming solar radiation during $\mathrm{HI}$ and AT heatwaves due to the cloud cover whereas the increase of low level moisture limits the thermal loss.

Nighttime heatwaves over Western Sahel in AMJ (Wn$A M J$ ): Fig. 10. They cover most of western Sahel and Guinea but have intensity anomalies of only moderate magnitude (less than one standard deviation) in comparison with other heatwave types. The thermal indices can be categorised into two groups on the basis of the synoptic conditions during these heatwaves. T, HI and NET heatwaves occur along with an increase of wind speed and cloud cover (Fig. S10) over the region of interest whilst the low level moisture shows a small decrease. Reversely during AT and UTCI heatwaves, the low level moisture increases significantly (magnitude comparable to that of temperature) whereas a decrease of wind speed is observed. Resultantly the thermodynamics also vary with these two groups of indices. For T, HI and NET, the processes consist of small anomalies of longwave 


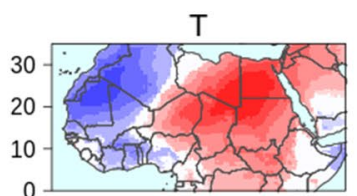

$\operatorname{Rad} T$

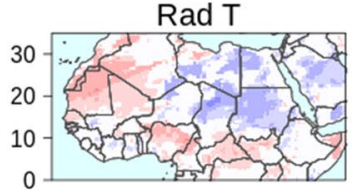

SHF T

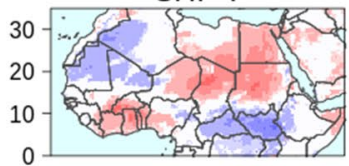

T-Adv T

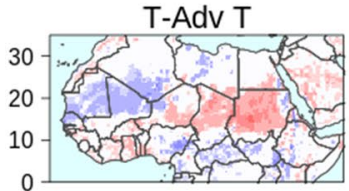

$\mathrm{RH} \mathrm{T}$

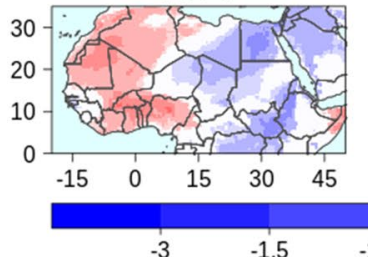

$-3$

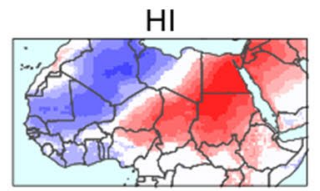

$\mathrm{Rad} \mathrm{HI}$

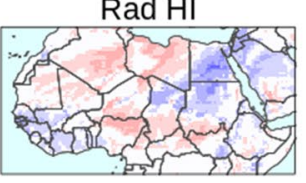

SHF HI

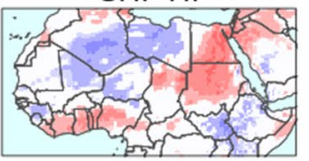

T-Adv HI

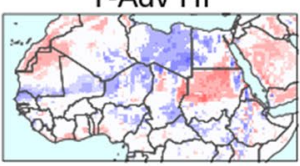

$\mathrm{RH} \mathrm{HI}$

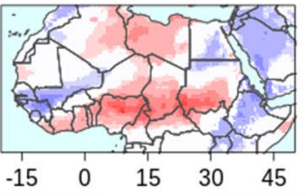

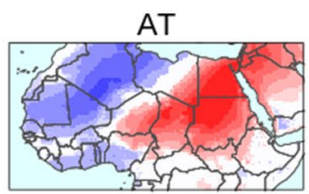

Rad AT

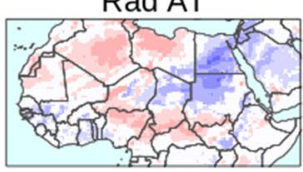

SHF AT

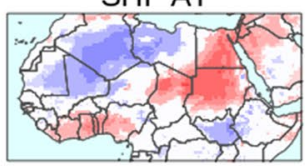

T-Adv AT

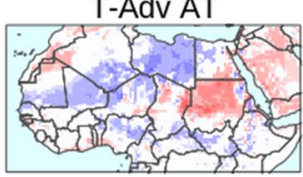

RH AT

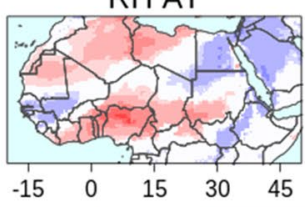

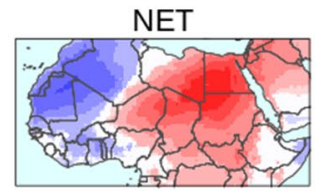

Rad NET

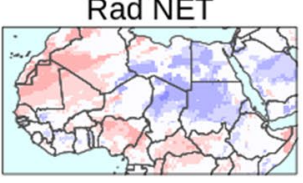

SHF NET

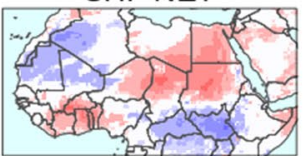

T-Adv NET

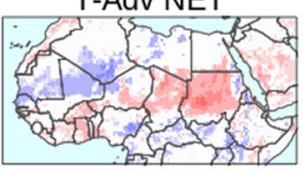

RH NET

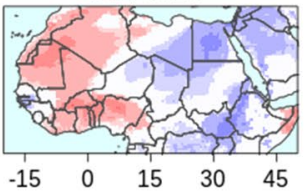

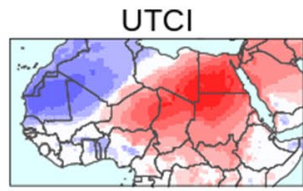

Rad UTCl

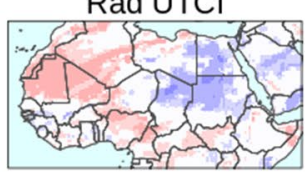

SHF UTCI

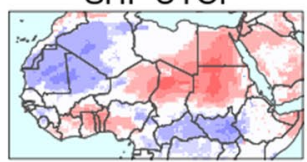

T-Adv UTCI

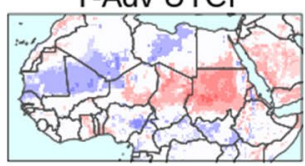

$\mathrm{RH}$ UTCl

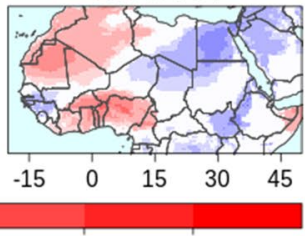

Fig. 9 Same as Fig. 8 but for heatwaves occurring at daytime over Eastern Sahel during the AMJ season (Ed-AMJ)

radiation. In AT and UTCI heatwaves, the increase of longwave radiation is well marked (in excess of 0.5 standard deviation). They also have two additional sources of heating: (1) sensible heat flux from the surface and (2) small heat advection in the lower atmosphere. Therefore, unlike with Ed-AMJ events, the difference in synoptic conditions is also reflected in the thermodynamic quantities.

Nighttime heatwaves over eastern Sahel in AMJ (En$A M J)$ : Fig. 11. They extend in a southwest-northeast axis from the eastern Sahel to the northeast Sahara where the intensity is greatest. As in Ed-FM they show the highest agreement between the thermodynamic conditions sampled from the different heatwave indices. Indeed all show a large increase of moisture and cloud cover which is the most important in AT and UTCI heatwaves where the magnitude of the moisture anomaly almost equates to that of temperature. There is also a consistent decrease in wind speed across all indices (Fig. S10).

En-AMJ heatwaves occur as a result of (1) primarily longwave warming and (2) sensible heat flux from the soil. The longwave warming extends from the equatorial West Africa region northeastward to the northeast coast of Africa with magnitude peaking to above one standard deviation in AT and UTCI. The sensible heat flux is mainly confined within the southern half of eastern Sahel and its magnitude also goes up to 0.4 standard deviation.

Summarily the thermodynamics and synoptic conditions vary between daytime and nighttime and between eastern and western Sahel. Furthermore, there is a lower agreement between the FM and the AMJ daytime heatwaves over western Sahel than over eastern Sahel. However there is an overall better consistency of the thermodynamic processes across heatwaves indices (Table 4) than what the low Jaccard coefficients suggest.

\section{Discussion}

From an operational perspective, the low coincidence between heatwaves detected from different indices over the same diurnal period may have profound implications for heatwave prediction and early warning given that many countries (including in the Sahel) only consider a single index in their operational systems (WMO-No.1142, 2015). Using one particular index rather than another will necessarily lead to missing out heatwave events identified by the other indices, which could nonetheless be more relevant to a given group of vulnerable populations. It is thus 


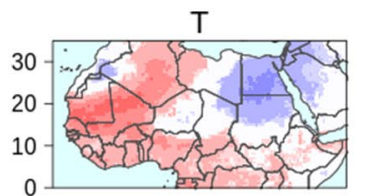

$\operatorname{Rad} T$

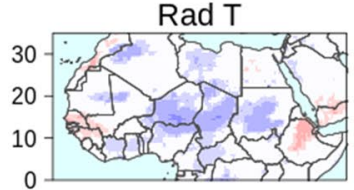

SHF T

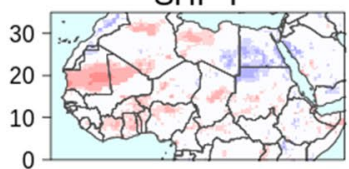

T-Adv T

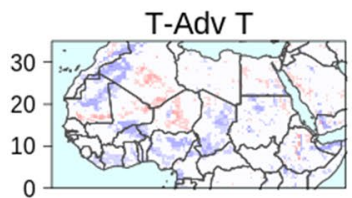

$\mathrm{RH} \mathrm{T}$

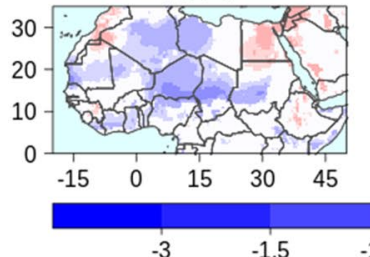

$-3$

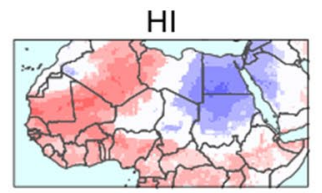

$\mathrm{Rad} \mathrm{HI}$

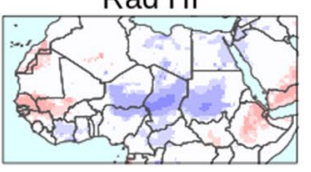

SHF HI

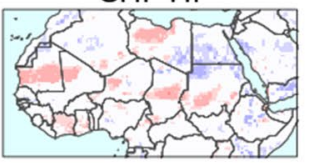

T-Adv HI

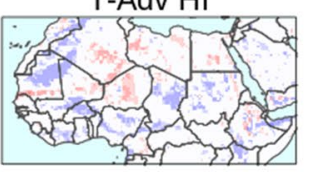

$\mathrm{RH} \mathrm{HI}$

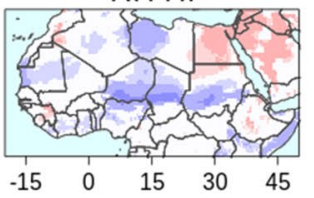

$-1.2$

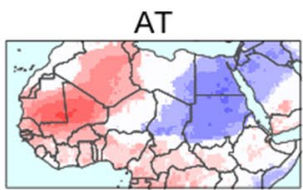

Rad AT

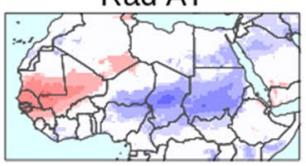

SHF AT

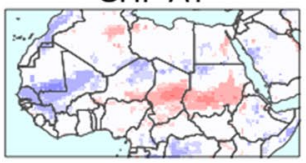

T-Adv AT

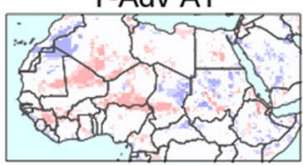

RH AT

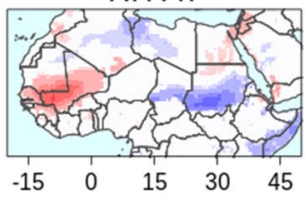

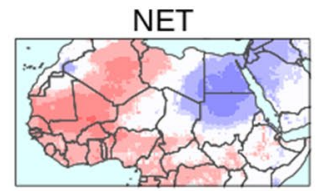

Rad NET

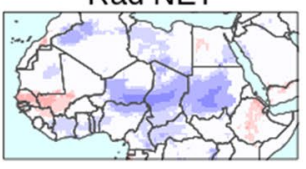

SHF NET

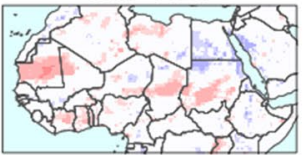

T-Adv NET

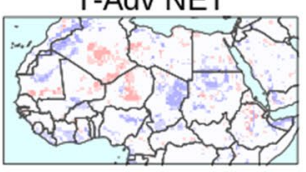

RH NET

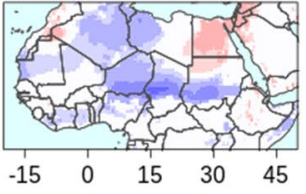

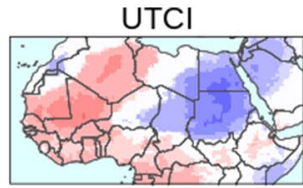

Rad UTCI

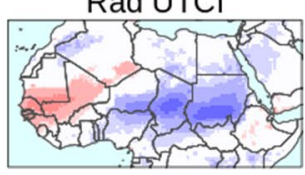

SHF UTCI

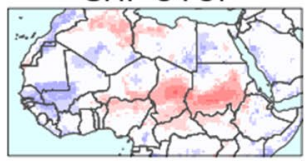

T-Adv UTCI

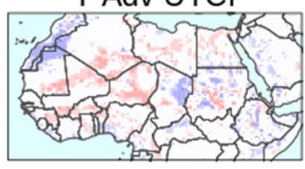

$\mathrm{RH}$ UTCl

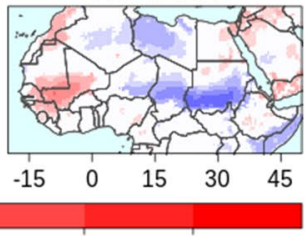

Fig. 10 Same as Fig. 8 but for heatwaves occurring over Western Sahel at nighttime during the AMJ season (Wn-AMJ)

recommended to monitor a range of indices in order to target various socio-economic groups of vulnerable populations with the most index. Such an approach is relevant to the recent emphasis on multi-hazard impact-based forecasting (WMO-No. 1150, 2015) in which warnings seek to indicate potential damages of hydro-meteorological events on humans and their assets. For example, large proportions of Sahelian populations practice their economic activities outdoor and are exposed to relatively long hours of sunshine, including construction workers and street vendors in urban centres (Quak 2018; Balarabe and Sahin 2020), pastoralists and increasingly market gardeners (Woltering et al. 2011) and informal gold diggers (Ouedraogo and Mundler 2019) in rural areas. The UTCI index, which accounts for solar radiation (Table 1) may therefore be the most indicated for targeting these groups. From a spatial point of view, in the southernmost parts of the Sahel where the similarity is the lowest, it is important to use indices which give much weight to humidity (HI, AT and UTCI) as this region also has the largest moisture variability especially in AMJ. On the other hand, over the Northeastern parts of the domain as well as the whole Sahel during the FM season, only little value will be added to heat warnings that use complex indices because of small variability of environmental variables (see
Sect. 3.1.3). For these cases, mere temperature is a reasonably good choice.

The fact that only small proportions of heatwaves occur simultaneously at daytime and nighttime is an important information for risk management. There is evidence that hot days followed by hot nights indeed pose a greater threat to people (e.g., Schär 2016; Murage et al. 2017) because the body does not have a respite to the heat in such situations. As such, the lack of day/night synchronicity can be interpreted as a relieving factor for Sahelian populations. However the few (but dangerous) cases where both heatwave types are synchronous should not be overlooked.

In terms of underlying thermodynamic processes, despite differences of the sampling bases, comparisons of the findings of this paper with that of previous publications can still be made. Most notably our findings agree with Guichard (2014), Oueslati et al. (2017) and Sambou et al. (2020) on the leading role of greenhouse effect of moisture during Sahelian nighttime heatwaves. It should be noted that this process is not specific to the Sahel but is also observed during nighttime heatwaves over other tropical regions (e.g Oppermann et al. 2017; Chen et al. 2019). Likewise, the shortwave radiation at the southernmost part of the Sahel accompanying daytime heatwaves corroborates the findings 

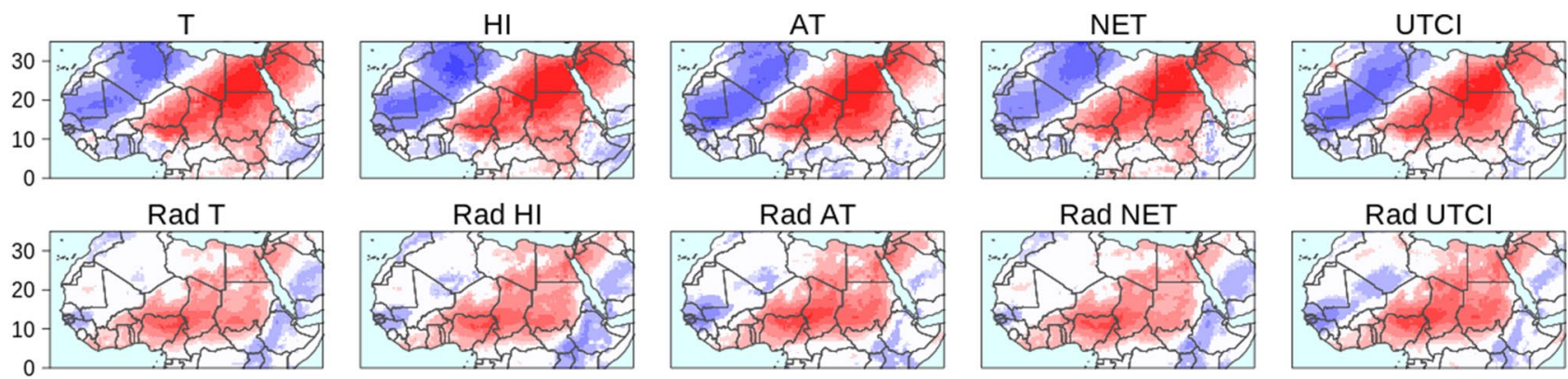

$\mathrm{Rad} \mathrm{HI}$

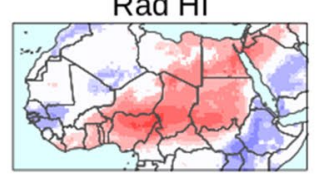

Rad AT

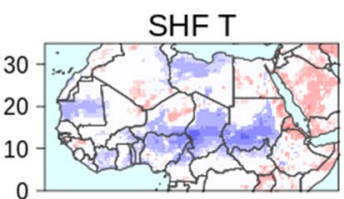

T-Adv T

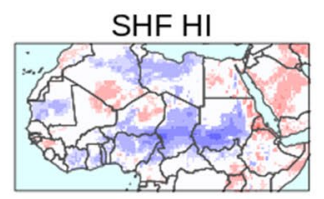

T-Adv HI
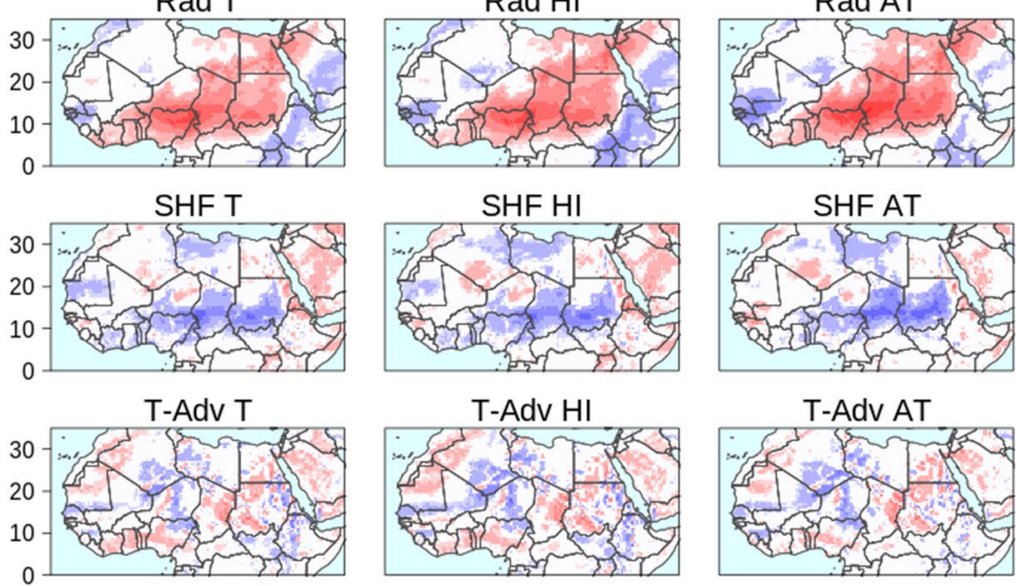

Rad NET

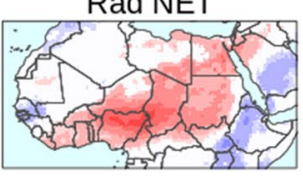

Rad UTCI
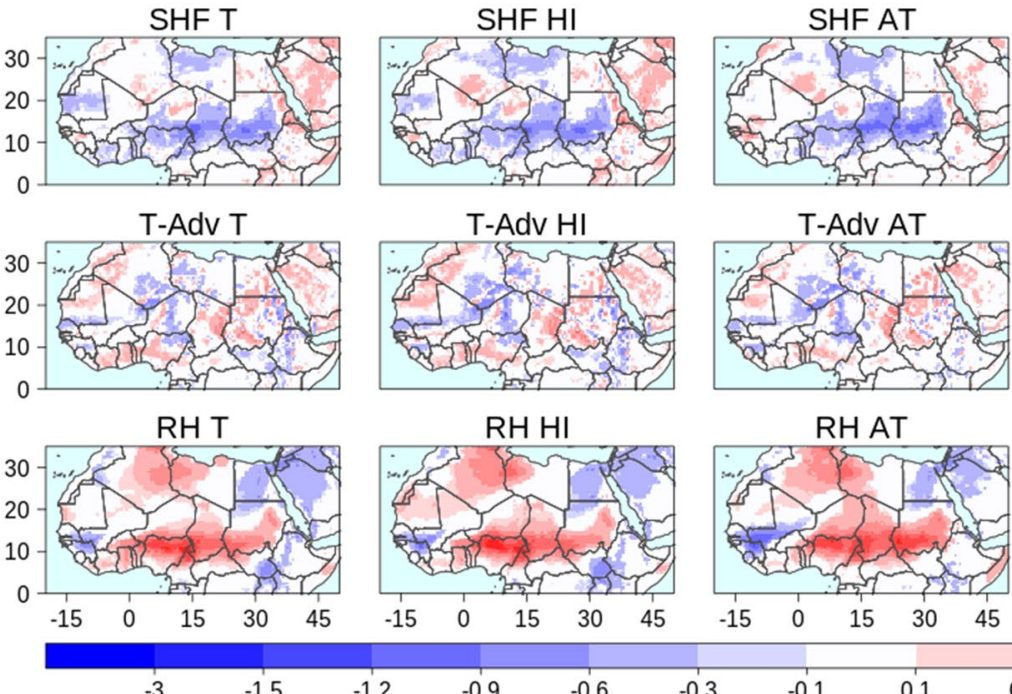

SHF NET

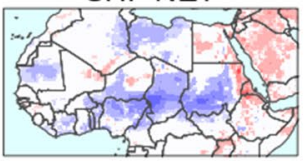

T-Adv NET
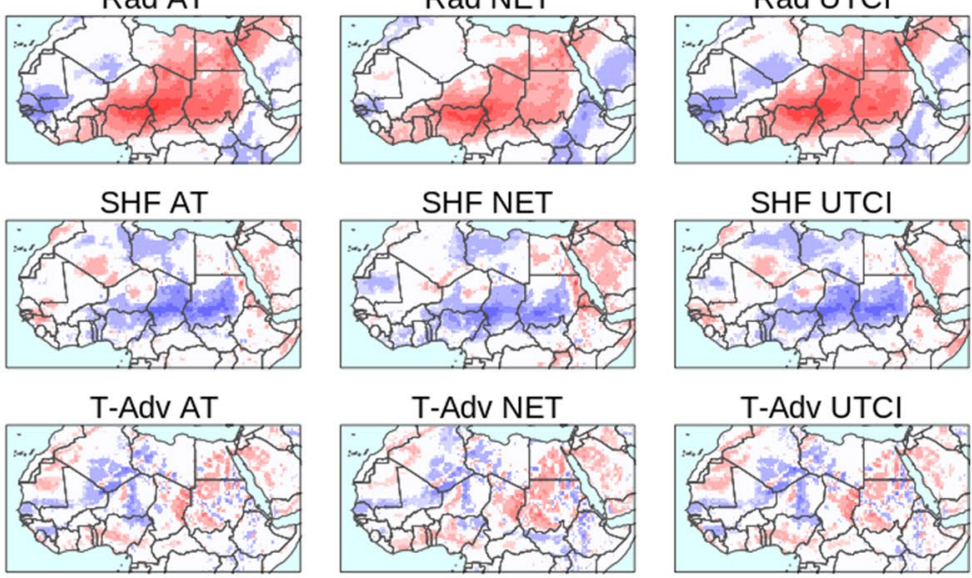

SHF UTCI

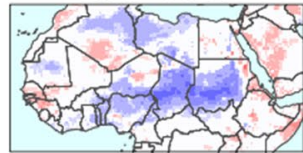

T-Adv UTCI

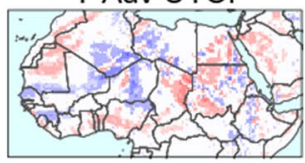

RH AT

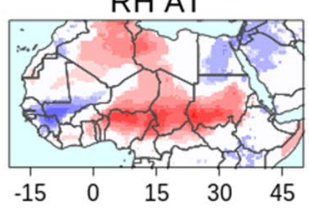

RH NET

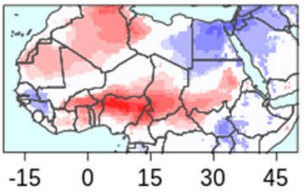

$\mathrm{RH}$ UTCl

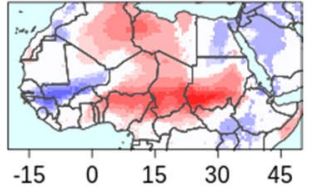

$-1.2$

$-0.9$

$-0.6$

$-0.3$

$-0.1$

0.1

0.3

0.6

0.9

1.2

1.53

Fig. 11 Same as Fig. 8 but for heatwaves occurring over Eastern Sahel at nighttime during the AMJ season (En-AMJ)

of (Oueslati et al. 2017) and is also found to drive some heatwaves in midlatitude areas like Europe (e.g Lhotka et al. 2018).

In addition, this paper clearly highlighted the key role played by thermal advection in the occurrence of Sahelian heatwaves which was suggested by Moron et al. (2018) for weather types. Hot air is indeed conveyed from the continental eastern Sahel towards the cooler western coast on one hand and from the southernmost parts of the Sahel to its northernmost parts on the other hand (see Sect. 3.3). The importance of this process to heatwaves has also been proved over other regions (Cerne et al. 2007; Jacques-Coper et al. 2016; Sfî̀că et al. 2017).

Interpretation of our results on thermodynamic processes must however bear in mind the limitation of the ERA5 reanalysis data on which they are based. There is a considerable uncertainty in many meteorological fields between various reanalyses (Roberts et al. 2014, 2017) notably for some of the key radiative quantities of water vapour, clouds and dust. Dust is a crucial component of the Sahelian atmosphere (Knippertz and Todd 2012) and its radiative contribution to the atmospheric heat budget (Alamirew et al. 2018) may then be an important parameter for heatwaves. Furthermore there is a clear need for improved observations across the
Sahel to support assimilation into reanalyses and direct process analysis.

But notwithstanding this, the main findings of this paper along with that from previous research give a clue as to what can be the large scale dynamical drivers of heatwaves over the Sahel. Thus, despite the dryness of the FM season, Ed-FM heatwaves are accompanied by important moisture anomalies in the western Sahel (Fig. 7) as well as positive rainfall anomalies over the Guinean region of West Africa (not shown). Additionally the low level circulation has a strong cyclonic anomaly (Fig. 12) causing moisture surges from the Atlantic. Such patterns recall the findings of studies (Fink and Knippertz 2003; Knippertz 2003; Knippertz and Martin 2005, 2007) investigating the causes of extramonsoon precipitation over West Africa. The invasion of the Atlantic air masses from a dynamical point of view happens as a consequence of a southward penetration of midlatitudes Rossby waves, potentially leading to the well-known tropical plumes. It is therefore likely that the build-up stage of tropical plumes be favourable to heatwave occurrence over the Sahel.

During the AMJ season, heatwaves over eastern Sahel are also associated with a cyclonic turning of the low level wind over the Sahel with a strong southwesterly component 
$\overrightarrow{2 \mathrm{~m} / \mathrm{s}}$

(a) West day FM

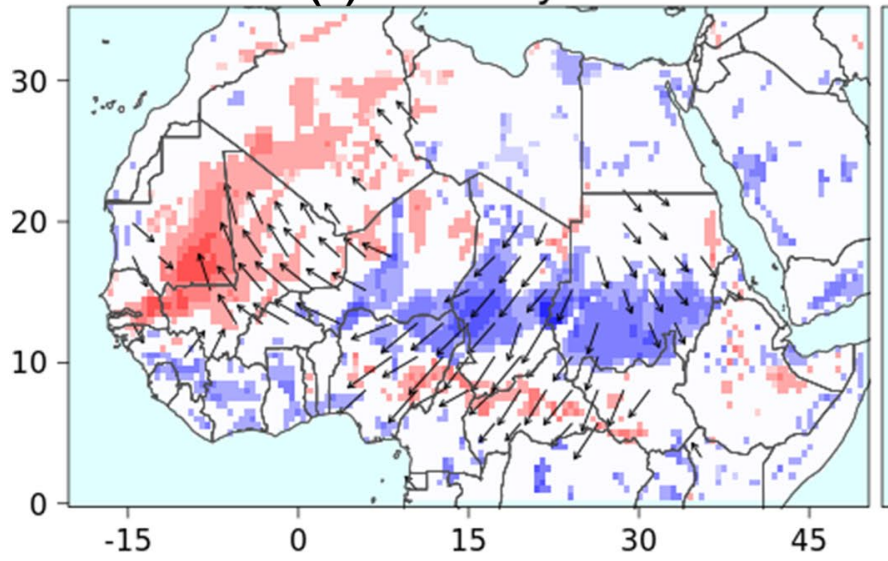

(c) West day AMJ

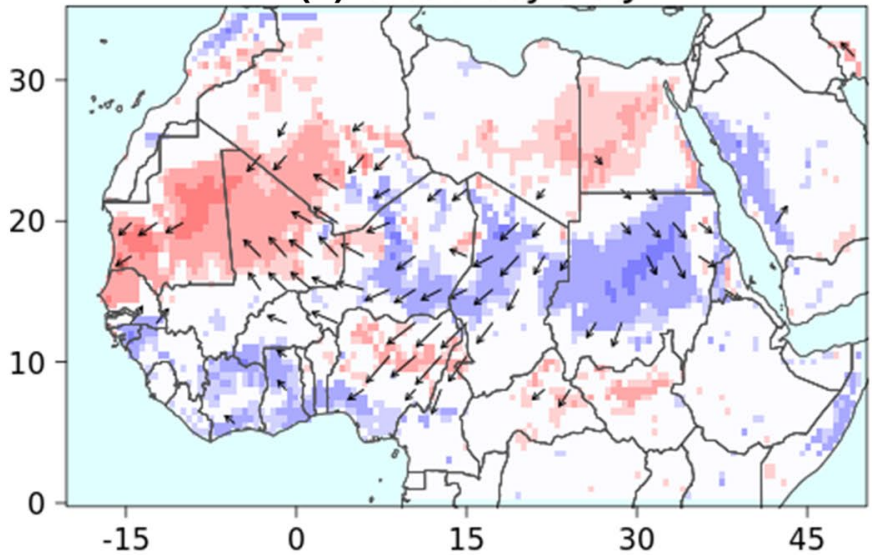

(e) West night AMJ

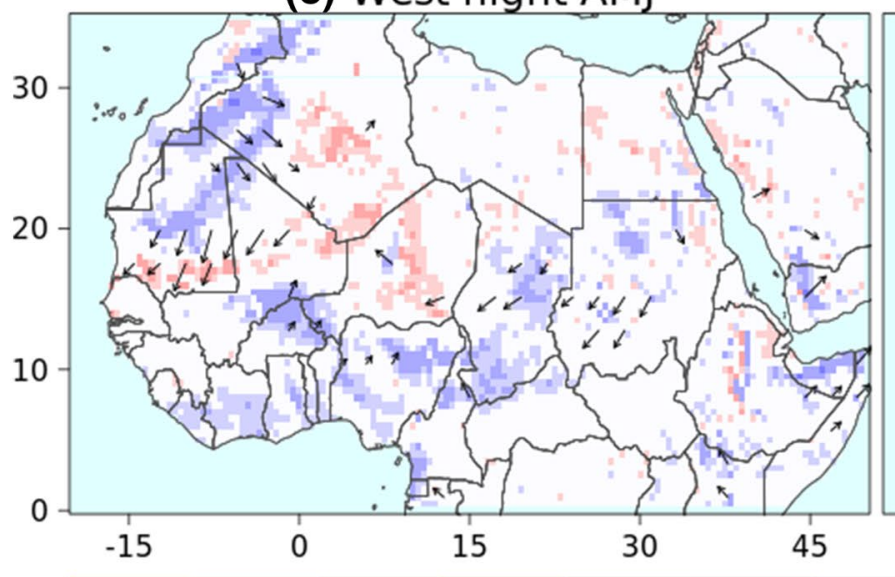

(b) East day FM

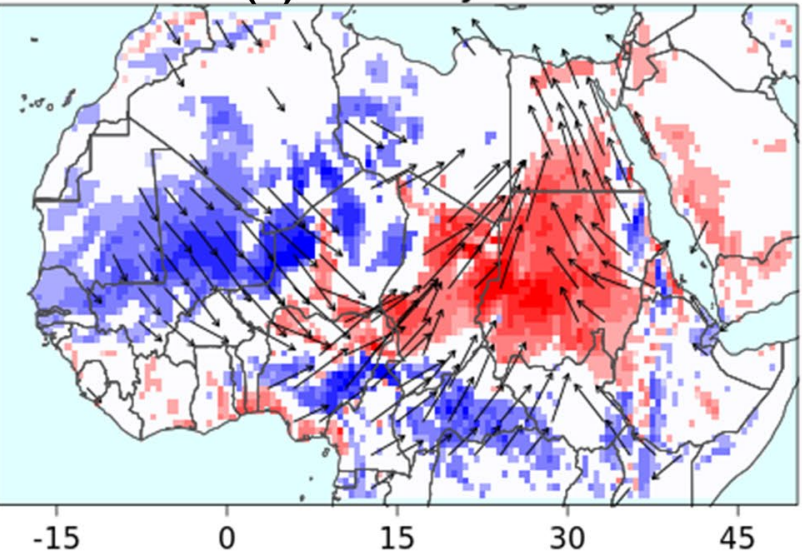

(d) East day AMJ

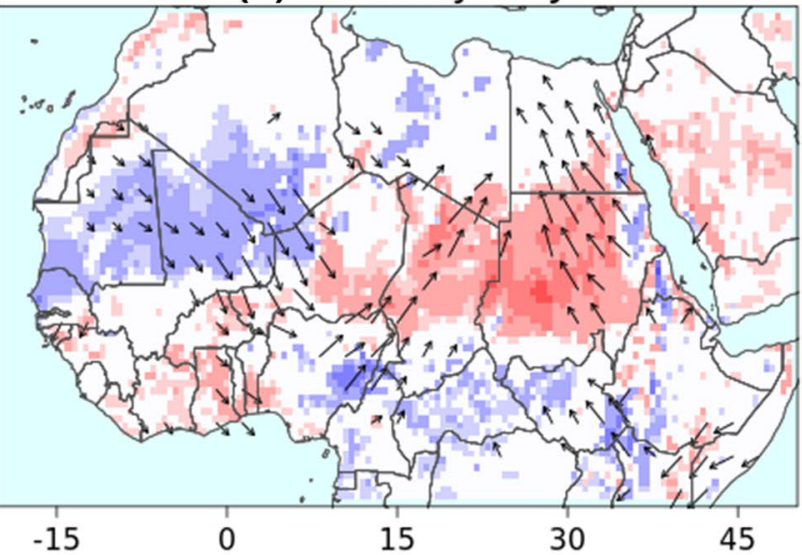

(f) East night AMJ

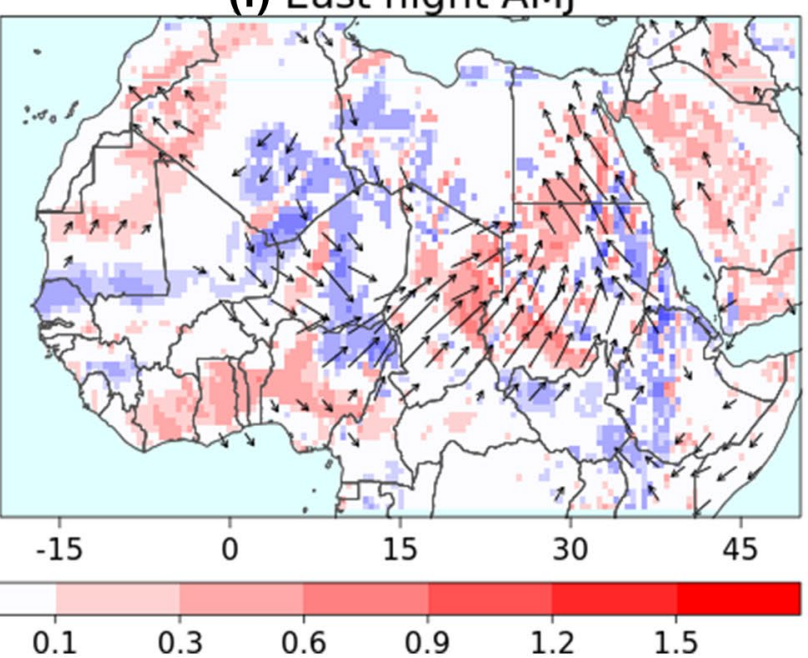

Fig. 12 Normalised anomalies of temperature advection (shades) and wind speed (vectors) associated with heatwaves detected using T. Only anomalies significant at the 0.05 probability level are plotted

(Fig. 12). Conversely, heatwaves over western Sahel coincide with a reinforcement of the Harmattan winds. The AMJ season is also the period during which the Guinean region experiences the first peak of the West African Monsoon (WAM, Gu and Adler 2004; Nguyen et al. 2011; Thorncroft et al. 2011). This suggests a potential link between the 
monsoon and heatwaves similarly to other tropical regions (Ghatak et al. 2017; Luo and Lau 2018).

In connection with the cyclonic and anticyclonic turning of low level winds, there may be a substantial modulation by the West African Heat Low (WAHL). This major climatic feature is indeed located within the Sahel band during the AMJ season (Lavaysse et al. 2009). During Sahelian heatwaves, its occurrence oscillates zonally between the west and the east of the Sahel laying almost exactly within the heatwave region (Fig. S11). Consequently a link may be found with heatwaves (at least statistically) but this requires deeper investigations.

So three large scale drivers including mid-latitudes Rossby waves, the WAM over the equatorial region and the WAHL are likely to impact the occurrence of Sahelian heatwaves at the synoptic to intraseasonal timescales. The benefit in exploring such connections lies in the potential predictability which will be explored in future work. A companion paper examines (Guigma et al. 2020, submitted) the dynamical processes governing heatwaves focusing on the role of the tropical modes of variability and their interaction with these circulation features.

\section{Conclusion and prospects}

This paper investigated synoptic to intraseasonal heatwaves in the West African Sahel. The purpose was to (1) derive and compare the statistical characteristics of these heatwaves in the Sahel using diverse multivariate thermal indices and (2) examine the underpinning thermodynamic processes. Consistently across the thermal indices used in this study heatwaves in the Sahel are characterized by short-lasting events (3-5 day duration) which occur once to twice a year and are associated with large magnitude. However, different thermal indices sample different events, most particularly between daytime and nighttime events, but also perhaps surprisingly there can be notable differences in the events identified between indices for the same diurnal period. This may be very important given the preponderance of single indices in most heatwave early warning systems around the world (WMO-No.1142, 2015). The most spatially extended events are characterized by a (thermal) zonal polarisation of the Sahel. Their underpinning thermodynamic processes vary from one index to another consistently with the differences in the samples. The most robust processes across all indices are warm air advection and longwave radiation.

The results suggest that the choice of thermal index is important with profound implications for: (1) Our scientific understanding of heat wave phenomena such that synthesising research results should recognise the diversity of characteristics, causes and thus potentially predictability across different indices and (2) operational risk management, in that we must ensure an appropriate choice of thermal index reflecting the risk to various exposed populations. Thus forecasters from Sahelian national meteorological services (NMSs) can target specific groups of the population (outdoor workers, farmers, and workers under shielded conditions etc.) based on the typical features of each index. This will grant more efficiency and probably more trust to the heatwave warnings which is important for co-production.

Furthermore, a regional scale Early Warning-Early Action plan can make use of the definition and characterization of heatwaves of the present paper. Through the double magnitude constraint, there is a certitude of sampling only extremely hot events that may require humanitarian actions. However, there is a clear need to extend this scientific analysis towards understanding the actual impact on society and/ or the environment. Appropriate thresholds of heatwave magnitude and duration should be defined in conjunction with relevant stakeholders based on data and experience of the diverse impacts across differing levels of exposure and vulnerability. Such impact-based forecasting methods are being developed (Weyrich et al. 2018; Potter et al. 2018) and should be considered for the heatwave risk management in the Sahel.

For example in the health sector there is a growing body of research into the link between heat and health (e.g., Lam et al. 2013; Herrmann and Sauerborn 2018; Campbell et al. 2018) at the global level. Using multiple thermal indices can lead to a better simulation of the heat-health relationship (e.g Kim et al. 2011; Morabito et al. 2014). The present study provides a basis for such investigations over the Sahel through identifying and statistically characterising a variety of indices which simulate various heat hazards as well as elaborating on the physical causes behind them. In fact, quantifying the link between heatwaves and health should now be a priority in future studies in the Sahel as this remains to date poorly explored.

Finally, in the logic of scaling FbA plans at the Sahel level, it is necessary to first assess the skill of forecast models in predicting relevant thermal indices. Given the differences in thermodynamic processes between indices identified in this paper we may expect differing levels of predictability. This requires further analysis to build on existing work (e.g., Batté et al. 2018; Perez et al. 2018) to extend to all thermal indices in an LSHW approach. This is the subject of ongoing work by the authors.

Acknowledgements KHG was supported by the Peter Carpenter Scholarship for African Climate Science at the University of Sussex, UK. Further support was provided through the (1) UK NERC/ESRC/DfID Science for Humanitarian Emergencies and Resilience (SHEAR) consortium project 'Towards Forecast-based Preparedness Action' (ForPAc, www.forpac.org), grant number NE/P000673/1 and (2) Future Climate for Africa (FCFA) regional consortium project 'AMMA-2050', grant number NE/M02024X/1. 
Open Access This article is licensed under a Creative Commons Attribution 4.0 International License, which permits use, sharing, adaptation, distribution and reproduction in any medium or format, as long as you give appropriate credit to the original author(s) and the source, provide a link to the Creative Commons licence, and indicate if changes were made. The images or other third party material in this article are included in the article's Creative Commons licence, unless indicated otherwise in a credit line to the material. If material is not included in the article's Creative Commons licence and your intended use is not permitted by statutory regulation or exceeds the permitted use, you will need to obtain permission directly from the copyright holder. To view a copy of this licence, visit http://creativecommons.org/licenses/by/4.0/.

\section{References}

Adeniyi MO, Oyekola SO (2017) Assessment of heat and cold wave events over West Africa using three regional climate models. Ann Geophys 60:0322. https://doi.org/10.4401/ag-7039

Alamirew NK, Todd MC, Ryder CL et al (2018) The early summertime Saharan heat low: sensitivity of the radiation budget and atmospheric heating to water vapour and dust aerosol. Atmos Chem Phys 18:1241-1262

Anderberg MR (1973) Cluster analysis for applications. Academic Press, New York

Añel JA, Fernández-González M, Labandeira X et al (2017) Impact of cold waves and heat waves on the energy production sector. Atmosphere 8:209. https://doi.org/10.3390/atmos8110209

Arbuthnott KG, Hajat S (2017) The health effects of hotter summers and heat waves in the population of the United Kingdom: a review of the evidence. Environ Health 16:119. https://doi. org/10.1186/s12940-017-0322-5

Balarabe MK, Sahin M (2020) Metaspace, mobility and resistance: understanding vendors' movement pattern as a resistive strategy in Kano, Nigeria. J Asian Afr Stud. https://doi.org/10.1177/00219 09620905055

Barbier J, Guichard F, Bouniol D et al (2017) Detection of intraseasonal large-scale heat waves: characteristics and historical trends during the Sahelian spring. J Clim 31:61-80. https://doi. org/10.1175/JCLI-D-17-0244.1

Barriopedro D, Fischer EM, Luterbacher J et al (2011) The hot summer of 2010: redrawing the temperature record map of Europe. Science 332:220-224. https://doi.org/10.1126/science.1201224

Batté L, Ardilouze C, Déqué M (2018) Forecasting West African heat waves at subseasonal and seasonal time scales. Mon Weather Rev 146:889-907. https://doi.org/10.1175/MWR-D-17-0211.1

Berman A, Horovitz T, Kaim M, Gacitua H (2016) A comparison of THI indices leads to a sensible heat-based heat stress index for shaded cattle that aligns temperature and humidity stress. Int J Biometeorol 60:1453-1462. https://doi.org/10.1007/s0048 4-016-1136-9

Black H (2010) When to Warn? Comparing heat indices to evaluate public health risks. Environ Health Perspect 118:A35

Blazejczyk K, Epstein Y, Jendritzky G, Staiger H, Tinz B (2012) Comparison of UTCI to selected thermal indices. Int J Biometeorol 56:515-535. https://doi.org/10.1007/s00484-011-0453-2

Bourgeois E, Bouniol D, Couvreux F, Guichard F, Marsham JH, Garcia-Carreras L, Birch CE, Parker DJ (2018) Characteristics of mid-level clouds over West Africa. Q J R Meteorol Soc 144:426442. https://doi.org/10.1002/qj.3215

Bröde P, Fiala D, Błażejczyk K, Holmér I, Jendritzky G, Kampmann B, Tinz B, Havenith G (2012) Deriving the operational procedure for the Universal Thermal Climate Index (UTCI). Int J Biometeorol 56:481-494. https://doi.org/10.1007/s00484-011-0454-1
Campbell S, Remenyi TA, White CJ, Johnston FH (2018) Heatwave and health impact research: a global review. Health Place 53:210-218. https://doi.org/10.1016/j.healthplace.2018.08.017

Ceccherini G, Russo S, Ameztoy I et al (2017) Heat waves in Africa 1981-2015, observations and reanalysis. Nat Hazards Earth Syst Sci 17:115-125. https://doi.org/10.5194/nhess-17-115-2017

Cerne SB, Vera CS, Liebmann B (2007) The nature of a heat wave in Eastern Argentina occurring during SALLJEX. Mon Weather Rev 135:1165-1174. https://doi.org/10.1175/MWR3306.1

Chapman L, Azevedo JA, Prieto-Lopez T (2013) Urban heat and critical infrastructure networks: a viewpoint. Urban Clim 3:7-12. https://doi.org/10.1016/j.uclim.2013.04.001

Cheng Y, Niu J, Gao N (2012) Thermal comfort models: a review and numerical investigation. Build Environ 47:13-22. https://doi. org/10.1016/j.buildenv.2011.05.011

Chen X, Li N, Liu J et al (2019) Global heat wave hazard considering humidity effects during the 21st century. Int J Environ Res Public Health. https://doi.org/10.3390/ijerph16091513

Coates L, Haynes K, O'Brien J et al (2014) Exploring 167 years of vulnerability: an examination of extreme heat events in Australia 1844-2010. Environ Sci Policy 42:33-44. https://doi. org/10.1016/j.envsci.2014.05.003

Collins M, Knutti R, Arblaster J et al (2013) Long-term climate change: projections, commitments and irreversibility. Climate change 2013 - the physical science basis: contribution of working group I to the fifth assessment report. Intergovernmental Panel on Climate Change, Geneva, pp 1029-1136

Copernicus Climate Change Service (C3S) (2017): ERA5: Fifth generation of ECMWF atmospheric reanalyses of the global climate. Copernicus Climate Change Service Climate Data Store (CDS). https://cds.climate.copernicus.eu/cdsapp\#!/home

Couvreux F, Guichard F, Bock O, Campistron B, Lafore J-P, Redelsperger J-L (2010) Synoptic variability of the monsoon flux over West Africa prior to the onset. Q J R Meteorol Soc 136:159-173. https://doi.org/10.1002/qj.473

Cuxart J, Conangla L, Jiménez MA (2015) Evaluation of the surface energy budget equation with experimental data and the ECMWF model in the Ebro Valley. J Geophys Res Atmos 120:1008-1022. https://doi.org/10.1002/2014JD022296

Davidson O, Halsnæs K, Huq S et al (2003) The development and climate nexus: the case of sub-Saharan Africa. Clim Policy 3:S97S113. https://doi.org/10.1016/j.clipol.2003.10.007

Dee DP, Uppala SM, Simmons AJ et al (2011) The ERA5nterim reanalysis: configuration and performance of the data assimilation system. Q J R Meteorol Soc 137:553-597. https://doi. org/10.1002/qj.828

de Freitas CR, Grigorieva EA (2015a) A comprehensive catalogue and classification of human thermal climate indices. Int J Biometeorol 59:109-120. https://doi.org/10.1007/s00484-014-0819-3

de Freitas CR, Grigorieva EA (2015b) Role of acclimatization in weather-related human mortality during the transition seasons of autumn and spring in a thermally extreme mid-latitude continental climate. Int J Environ Res Public Health 12:14974-14987. https://doi.org/10.3390/ijerph121214962

de Freitas CR, Grigorieva EA (2017) A comparison and appraisal of a comprehensive range of human thermal climate indices. Int J Biometeorol 61:487-512. https://doi.org/10.1007/s0048 4-016-1228-6

de Perez EC, van Aalst M, Bischiniotis K et al (2018) Global predictability of temperature extremes. Environ Res Lett 13:054017. https://doi.org/10.1088/1748-9326/aab94a

Duchon CE (1979) Lanczos filtering in one and two dimensions. J Appl Meteor 18:1016-1022. https://doi.org/10.1175/15200450(1979)018<1016:LFIOAT > 2.0.CO;2

Ebi KL, Teisberg TJ, Kalkstein LS et al (2004) Heat watch/warning systems save lives: estimated costs and benefits for Philadelphia 
1995-98. Bull Am Meteorol Soc 85:1067-1074. https://doi. org/10.1175/BAMS-85-8-1067

Everitt B, Landau S, Leese M, Stahl D (2011) Cluster analysis. Wiley, Hoboken

Fink AH, Knippertz P (2003) An extreme precipitation event in southern Morocco in spring 2002 and some hydrological implications. Weather 58:377-387. https://doi.org/10.1256/wea.256.02

Fischer EM, Schär C (2010) Consistent geographical patterns of changes in high-impact European heatwaves. Nat Geosci 3:398403. https://doi.org/10.1038/ngeo866

Foken T (2008) The energy balance closure problem: an overview. Ecol Appl 18:1351-1367. https://doi.org/10.1890/06-0922.1

Fontaine B, Janicot S, Monerie P-A (2013) Recent changes in air temperature, heat waves occurrences, and atmospheric circulation in Northern Africa. J Geophys Res 118:8536-8552. https://doi. org/10.1002/jgrd.50667

Gachon P, Bussières L, Gosselin P, Raphoz M, Bustinza R, Martin P, Dueymes G, Gosselin D, Labrecque S, Jeffers S, Yagouti A (2016) Guide to identifying alert thresholds for heat waves in Canada based on evidence. Co-edited by Université du Québec à Montréal, Environment and Climate Change Canada, Institut National de Santé Publique du Québec, and Health Canada, Montréal, Québec, Canada, p 71.

García-Herrera R, Díaz J, Trigo RM et al (2010) A review of the European summer heat wave of 2003. Crit Rev Environ Sci Technol 40:267-306. https://doi.org/10.1080/10643380802238137

Gasparrini A, Armstrong B (2011) The impact of heat waves on mortality. Epidemiology 22:68-73. https://doi.org/10.1097/ EDE.0b013e3181fdcd99

Ghatak D, Zaitchik B, Hain C, Anderson M (2017) The role of local heating in the 2015 Indian Heat Wave. Sci Rep 7:7707. https:// doi.org/10.1038/s41598-017-07956-5

Gounou A, Guichard F, Couvreux F (2012) Observations of diurnal cycles over a west african meridional transect: pre-monsoon and full-monsoon seasons. Bound Layer Meteorol 144:329-357. https://doi.org/10.1007/s10546-012-9723-8

Gu G, Adler RF (2004) Seasonal evolution and variability associated with the West African Monsoon System. J Clim 17:3364-3377. https://doi.org/10.1175/1520-0442(2004)017<3364:SEAVA $\mathrm{W}>2.0 . \mathrm{CO} ; 2$

Guichard F (2014) Thermodynamic processes shaping Sahelian heat waves: analysis of selected case studies. AGU, Washington

Guichard F, Kergoat L, Mougin E et al (2009) Surface thermodynamics and radiative budget in the Sahelian Gourma: seasonal and diurnal cycles. J Hydrol 375:161-177. https://doi.org/10.1016/j. jhydrol.2008.09.007

Guigma K H, Guichard F, Todd M, Peyrille P, Wang Y (2020) Atmospheric tropical modes are important drivers of Sahelian heatwaves. Clim Dyn (submitted)

Guirguis K, Gershunov A, Tardy A, Basu R (2013) The impact of recent heat waves on human health in California. J Appl Meteorol Climatol 53:3-19. https://doi.org/10.1175/JAMC-D-13-0130.1

Hannachi A, Jolliffe IT, Stephenson DB, Trendafilov N (2006) In search of simple structures in climate: simplifying EOFs. Int $\mathbf{J}$ Climatol 26:7-28. https://doi.org/10.1002/joc.1243

Hannachi A, Jolliffe IT, Stephenson DB (2007) Empirical orthogonal functions and related techniques in atmospheric science: a review. Int J Climatol 27:1119-1152. https://doi.org/10.1002/ joc. 1499

Hartmann DL, Tank AMGK, Rusticucci M, et al (2013) Observations: atmosphere and surface. Climate Change 2013 the physical science basis. In: Working group I contribution to the fifth assessment report of the Intergovernmental Panel on Climate Change, pp 159-254. https://doi.org/10.1017/CBO9781107415324.008

Hentschel G (1987) A human biometeorology classification of climate for large and local scales. In Proceedings of WMO/HMO/UNEP ssymposium on climate and human health, Leningrad 1986, vol 1, WCPA-No. 1, WMO. K

Herrmann A, Sauerborn R (2018) General practitioners' perceptions of heat health impacts on the elderly in the face of climate changea qualitative study in Baden-Württemberg, Germany. Int J Environ Res Public Health. https://doi.org/10.3390/ijerph15050843

Jacques-Coper M, Brönnimann S, Martius O et al (2016) Summer heat waves in southeastern Patagonia: an analysis of the intraseasonal timescale. Int J Climatol 36:1359-1374. https://doi.org/10.1002/ joc. 4430

Kalapureddy MCR, Lothon M, Campistron B, Lohou F, Saïd F (2010) Wind profiler analysis of the African Easterly Jet in relation with the boundary layer and the Saharan heat-low. Q J R Meteorol Soc 136:77-91. https://doi.org/10.1002/qj.494

Kim Y-M, Kim S, Cheong H-K, Kim E-H (2011) Comparison of temperature indexes for the impact assessment of heat stress on heat-related mortality. Environ Health Toxicol. https://doi. org/10.5620/eht.2011.26.e2011009

Knippertz P (2003) Tropical-extratropical interactions causing precipitation in Northwest Africa: statistical analysis and seasonal variations. Mon Weather Rev 131:3069-3076. https://doi. org/10.1175/1520-0493(2003)131<3069:TICPIN>2.0.CO;2

Knippertz P, Martin JE (2005) Tropical plumes and extreme precipitation in subtropical and tropical West Africa. Q J R Meteorol Soc 131:2337-2365. https://doi.org/10.1256/qj.04.148

Knippertz P, Martin JE (2007) The role of dynamic and diabatic processes in the generation of cut-off lows over Northwest Africa. Meteorol Atmos Phys 96:3-19. https://doi.org/10.1007/s0070 3-006-0217-4

Knippertz P, Todd MC (2012) Mineral dust aerosols over the Sahara: meteorological controls on emission and transport and implications for modeling. Rev Geophys. https://doi.org/10.1029/2011R G000362

Krstić G (2011) Apparent temperature and air pollution vs elderly population mortality in metro vancouver. PLoS ONE. https:// doi.org/10.1371/journal.pone.0025101

Lam CKC, Loughnan M, Tapper N (2013) An exploration of temperature metrics for further developing the heat-health weather warning system in Hong Kong. In: International Scholarly Research Notices. https://www.hindawi.com/journals/isrn/2013/930238/. Accessed 8 Jan 2019

Lavaysse C, Flamant C, Janicot S et al (2009) Seasonal evolution of the West African heat low: a climatological perspective. Clim Dyn 33:313-330. https://doi.org/10.1007/s00382-009-0553-4

Lee H-J, Lee W-S, Yoo JH (2016) Assessment of medium-range ensemble forecasts of heat waves. Atmos Sci Lett 17:19-25. https ://doi.org/10.1002/asl.593

Leuning R, van Gorsel E, Massman WJ, Isaac PR (2012) Reflections on the surface energy imbalance problem. Agric For Meteorol 156:65-74. https://doi.org/10.1016/j.agrformet.2011.12.002

Lhotka O, Kyselý J, Plavcová E (2018) Evaluation of major heat waves' mechanisms in EURO-CORDEX RCMs over Central Europe. Clim Dyn 50:4249-4262. https://doi.org/10.1007/s0038 2-017-3873-9

Li PW, Chan ST (2000) Application of a weather stress index for alerting the public to stressful weather in Hong Kong. Meteorol Appl 7:369-375. https://doi.org/10.1017/S1350482700001602

Luo M, Lau N-C (2018) Synoptic characteristics, atmospheric controls, and long-term changes of heat waves over the Indochina Peninsula. Clim Dyn 51:2707-2723. https://doi.org/10.1007/s0038 2-017-4038-6

Macpherson RK (1962) The assessment of the thermal environment. Rev Occup Environ Med 19:151-164. https://doi.org/10.1136/ oem.19.3.151

Martens B, Schumacher DL, Wouters H, Muñoz-Sabater J, Verhoest NEC, Miralles DG (2020) Evaluating the surface energy 
partitioning in ERA5. Geosci Model Dev Discuss. https://doi. org/10.5194/gmd-2019-315

Masato G, Bone A, Charlton-Perez A et al (2015) Improving the health forecasting alert system for cold weather and heat-waves in england: a proof-of-concept using temperature-mortality relationships. PLoS ONE 10:e0137804. https://doi.org/10.1371/journ al.pone. 0137804

Miralles DG, Teuling AJ, van Heerwaarden CC, Vilà-Guerau de Arellano J (2014) Mega-heatwave temperatures due to combined soil desiccation and atmospheric heat accumulation. Nat Geosci 7:345-349. https://doi.org/10.1038/ngeo2141

Morabito M, Crisci A, Messeri A et al (2014) Environmental temperature and thermal indices: what is the most effective predictor of heat-related mortality in different geographical contexts? Sci World J 2014:961750. https://doi.org/10.1155/2014/961750

Moron V, Oueslati B, Pohl B et al (2016) Trends of mean temperatures and warm extremes in northern tropical Africa (1961-2014) from observed and PPCA-reconstructed time series. J Geophys Res Atmos 121:5298-5319. https://doi.org/10.1002/2015JD024303

Moron V, Oueslati B, Pohl B, Janicot S (2018) Daily weather types in February-June (1979-2016) and temperature variations in Tropical North Africa. J Appl Meteor Climatol 57:1171-1195. https:// doi.org/10.1175/JAMC-D-17-0105.1

Murage P, Hajat S, Kovats RS (2017) Effect of night-time temperatures on cause and age-specific mortality in London. Environ Epidemiol 1:e005. https://doi.org/10.1097/EE9.0000000000000005

Nairn J, Fawcett R (2013) Defining heatwaves: heatwave defined as a heat-impact event servicing all community and business sectors in Australia. Centre for Australian Weather and Climate Research, Sydney, p 96

Nangombe SS, Zhou T, Zhang W, Zou L, Li D (2019) High-temperature extreme events over Africa under 1.5 and $2{ }^{\circ} \mathrm{C}$ of global warming. J Geophys Res Atmos 124:4413-4428. https://doi. org/10.1029/2018JD029747

Napoli CD, Barnard C, Prudhomme C, Cloke HL, Pappenberger F (2020) ERA5-HEAT: A global gridded historical dataset of human thermal comfort indices from climate reanalysis. Geosci Data J. https://doi.org/10.1002/gdj3.102

Nguyen H, Thorncroft CD, Zhang C (2011) Guinean coastal rainfall of the West African Monsoon. Q J R Meteorol Soc 137:1828-1840. https://doi.org/10.1002/qj.867

Nicholson SE (2018) Climate of the Sahel and West Africa. Oxford Res Encycl Clim Sci. https://doi.org/10.1093/acrefore/9780190228 620.013 .510

Olauson J (2018) ERA5: the new champion of wind power modelling? Renew Energy 126:322-331. https://doi.org/10.1016/j. renene.2018.03.056

Oppermann E, Brearley M, Law L et al (2017) Heat, health, and humidity in Australia's monsoon tropics: a critical review of the problematization of 'heat' in a changing climate. Wiley Interdiscip Rev Clim Change 8:e468. https://doi.org/10.1002/wcc.468

Ouedraogo LS, Mundler P (2019) Local Governance and Labor Organizations on Artisanal Gold Mining Sites in Burkina Faso. Sustainability 11:616. https://doi.org/10.3390/su11030616

Oueslati B, Pohl B, Moron V et al (2017) Characterization of heat waves in the Sahel and associated physical mechanisms. J Clim 30:3095-3115. https://doi.org/10.1175/JCLI-D-16-0432.1

Palin EJ, Thornton HE, Mathison CT et al (2013) Future projections of temperature-related climate change impacts on the railway network of Great Britain. Clim Change 120:71-93. https://doi. org/10.1007/s10584-013-0810-8

Panda DK, AghaKouchak A, Ambast SK (2017) Increasing heat waves and warm spells in India, observed from a multiaspect framework. J Geophys Res Atmos 122:3837-3858. https://doi. org/10.1002/2016JD026292
Pappenberger F, Jendritzky G, Staiger H et al (2015) Global forecasting of thermal health hazards: the skill of probabilistic predictions of the Universal Thermal Climate Index (UTCI). Int J Biometeorol 59:311-323. https://doi.org/10.1007/s00484-014-0843-3

Perkins SE (2015) A review on the scientific understanding of heatwaves - their measurement, driving mechanisms, and changes at the global scale. Atmos Res 164-165:242-267. https://doi. org/10.1016/j.atmosres.2015.05.014

Perkins SE, Alexander LV (2012) On the measurement of heat waves. J Clim 26:4500-4517. https://doi.org/10.1175/JCLI-D-12-00383.1

Perkins-Kirkpatrick SE, Gibson PB (2017) Changes in regional heatwave characteristics as a function of increasing global temperature. Sci Rep 7:12256. https://doi.org/10.1038/s41598-017$12520-2$

Perry A (2000) Impacts of climate change on tourism in the mediterranean: adaptive responses. Social Science Research Network, Rochester

Potter SH, Kreft PV, Milojev P et al (2018) The influence of impactbased severe weather warnings on risk perceptions and intended protective actions. Int J Disaster Risk Reduct 30:34-43. https:// doi.org/10.1016/j.ijdrr.2018.03.031

Quak E (2018) Drivers, challenges and opportunities for job creation in the Sahel: K4D helpdesk report 455. Institute of Development Studies, Brighton

Ramon J, Lledó L, Torralba V, Soret A, Doblas-Reyes FJ (2019) What global reanalysis best represents near-surface winds? Q J R Meteorol Soc 145:3236-3251. https://doi.org/10.1002/qj.3616

Richman MB (1986) Rotation of principal components. J Climatol 6:293-335. https://doi.org/10.1002/joc.3370060305

Roberts AJ, Marsham JH, Knippertz P (2014) Disagreements in low-level moisture between (re)analyses over summertime West Africa. Mon Weather Rev 143:1193-1211. https://doi. org/10.1175/MWR-D-14-00218.1

Roberts AJ, Marsham JH, Knippertz P et al (2017) New Saharan wind observations reveal substantial biases in analysed dust-generating winds. Atmos Sci Lett 18:366-372. https://doi.org/10.1002/ asl.765

Robinson PJ (2001) On the definition of a heat wave. J Appl Meteorol 40:762-775. https://doi.org/10.1175/15200450(2001) $040<0762$ :OTDOAH $>2.0 . C O ; 2$

Rohat G, Flacke J, Dosio A, Dao H, van Maarseveen M (2019) Projections of human exposure to dangerous heat in African cities under multiple socioeconomic and climate scenarios. Earth's Future 7:528-546. https://doi.org/10.1029/2018EF001020

Sambou M-JG, Janicot S, Pohl B, Badiane D, Dieng AL, Gaye A (2020) Heat wave occurrences over Senegal during spring: regionalization and synoptic patterns. Int J Climatol 40:440-457. https://doi.org/10.1002/joc.6220

Schär C (2016) The worst heat waves to come. Nat Clim Change 6:128-129. https://doi.org/10.1038/nclimate2864

Schoof JT, Ford TW, Pryor SC (2017) Recent changes in US regional heat wave characteristics in observations and reanalyses. $\mathrm{J}$ Appl Meteor Climatol 56:2621-2636. https://doi.org/10.1175/ JAMC-D-16-0393.1

Sfîcă L, Croitoru A-E, Iordache I, Ciupertea A-F (2017) Synoptic conditions generating heat waves and warm spells in Romania. Atmosphere 8:50. https://doi.org/10.3390/atmos8030050

Smith TT, Zaitchik BF, Gohlke JM (2013) Heat waves in the United States: definitions, patterns and trends. Clim Change 118:811825. https://doi.org/10.1007/s10584-012-0659-2

Smoyer-Tomic KE, Kuhn R, Hudson A (2003) Heat wave hazards: an overview of heat wave impacts in Canada. Nat Hazards 28:465486. https://doi.org/10.1023/A:1022946528157

Souch C, Grimmond S (2006) Applied climatology: urban climate. Prog Phys Geogr Earth Environ 30:270-279. https://doi. org/10.1191/0309133306pp484pr 
Steadman RG (1979) The assessment of sultriness. Part I: a temperature-humidity index based on human physiology and clothing science. J Appl Meteorol 18:861-873. https://doi.org/10.1175/15200450(1979)018<0861:TAOSPI > 2.0.CO;2

Steadman RG (1994) Norms of apparent temperature in Australia. Aust Meteorol Mag 43:1-16

Thorncroft CD, Nguyen H, Zhang C, Peyrillé P (2011) Annual cycle of the West African monsoon: regional circulations and associated water vapour transport. Q J R Meteorol Soc 137:129-147. https ://doi.org/10.1002/qj.728

Tschakert P (2007) Views from the vulnerable: understanding climatic and other stressors in the Sahel. Global Environ Change 17:381396. https://doi.org/10.1016/j.gloenvcha.2006.11.008

Weyrich P, Scolobig A, Bresch DN, Patt A (2018) Effects of impactbased warnings and behavioral recommendations for extreme weather events. Weather Clim Soc 10:781-796. https://doi. org/10.1175/WCAS-D-18-0038.1

Wilkinson E, Weingärtner L, Choularton R et al (2018) Forecasting hazards, averting disasters: implementing forecast-based early action at scale. Overseas Development Institute (ODI), London

Willett KM, Sherwood S (2012) Exceedance of heat index thresholds for 15 regions under a warming climate using the wet-bulb globe temperature. Int J Climatol 32:161-177. https://doi.org/10.1002/ joc. 2257

World Meteorological Organization and World Health Organization (2015) Heatwaves and health: guidance on warning-system development. WMO-No. 1142, Geneva.
World Meteorological Organization (2015) Guidelines on multi-hazard impact-based forecast and warning services. WMO-No.1150, Geneva

Woltering L, Pasternak D, Ndjeunga J (2011) The African market garden: the development of a low-pressure drip irrigation system for smallholders in the sudano sahel. Irrig Drain 60:613-621. https ://doi.org/10.1002/ird.610

Xu Z, FitzGerald G, Guo Y et al (2016) Impact of heatwave on mortality under different heatwave definitions: a systematic review and meta-analysis. Environ Int 89-90:193-203. https://doi. org/10.1016/j.envint.2016.02.007

Xu Z, Crooks JL, Black D et al (2017) Heatwave and infants' hospital admissions under different heatwave definitions. Environ Pollut 229:525-530. https://doi.org/10.1016/j.envpol.2017.06.030

Zhang K, Rood RB, Michailidis G et al (2012) Comparing exposure metrics for classifying "dangerous heat" in heat wave and health warning systems. Environ Int 46:23-29. https://doi.org/10.1016/j. envint.2012.05.001

Publisher's Note Springer Nature remains neutral with regard to jurisdictional claims in published maps and institutional affiliations. 